\title{
Flow cytometry for the assessment of animal sperm integrity and functionality: state of the art
}

\author{
Md. Sharoare Hossain ${ }^{1,2}$, Anders Johannisson ${ }^{1}$, Margareta Wallgren $^{1,3}$, Szabolcs Nagy ${ }^{2,4}$, \\ Amanda Pimenta Siqueira ${ }^{1}$ and Heriberto Rodriguez-Martinez ${ }^{5}$
}

Flow cytometry is now a recognized methodology within animal spermatology, and has moved from being a research tool to become routine in the assessment of animal semen destined to breeding. The availability of 'bench-top' flow cytometers and of newer and versatile markers for cell structure and function had allowed the instrumentation to measure more sperm parameters, from viability to reactiveness when exposed to exogenous stimuli, and to increase our capabilities to sort spermatozoa for potential fertilizing capacity, or chromosomal sex. The present review summarizes the state of the art regarding flow cytometry applied to animal andrology, albeit keeping an open comparative intent. It critically evaluates the present and future capabilities of flow cytometry for the diagnostics of potential fertility and for the development of current reproductive technologies such as sperm freezing, sperm selection and sperm sorting. The flow cytometry methods will probably further revolutionize our understanding of the sperm physiology and their functionality, and will undoubtedly extend its application in isolating many uncharacterized features of spermatozoa. However, continuous follow-up of the methods is a necessity owing to technical developments and the complexity of mapping spermatozoa. Asian Journal of Andrology (2011) 13,406-419; doi:10.1038/aja.2011.15; published online 11 April 2011

Keywords: animals; fertility; flow cytometry; semen analysis; spermatozoa; sperm functionality; sperm intactness

\section{INTRODUCTION}

Evaluation of the spermatozoa of animals has either a purpose of diagnosis of the health of the male reproductive organs or, for those sires destined to breeding, of the odds their semen has to fertilize (or, to lead to fertilization failure, depending on the approach to the problem). During clinical andrological examinations, evaluation of spermatozoa is of paramount importance, since sperm 'quality' provides an indication of the normality of testicular function in terms of sperm numbers, their viability (often simply determined by subjective motility judgment) and the normality of morphological features. As well, it provides an idea of the normality of the epididymal function, i.e. sperm maturation, with the display of proper morphological features (displacement of the cytoplasmic droplet from the neck to the annulus) and of activated motility after ejaculation. Fertilizing capacity, which is also reached during epididymal maturation, is not monitored by a simple spermiogram, and often only assessed after breeding by natural mating or artificial insemination (AI) of a certain number of females, the latter hopefully large enough to keep innate variation at minimum levels. Sperm functionality is, in this regard, obviously modulated or affected by the fluids spermatozoa bathe in, either as seminal plasma or as extenders used to decrease sperm concentration, or to allow cooling and freezing-thawing of sperm suspensions for AI.

There is a plethora of excellent reviews on this area of sperm evaluation and the reader is advised to consult these. ${ }^{1-14}$ Most of these reviews and the literature cited therein consistently concur to a basic fact; routine spermiogram evaluations are suitable to identify clear-cut cases of infertility and, sometimes, to provide cues for potential subfertility, but are not able to prognose levels of fertility of the semen (or the male) in question. ${ }^{7,13,15,16}$ The reason is quite obvious: such assessments simply evaluate basic variables of sperm appearance and viability, but cannot disclose subjacent structural details, biochemical and metabolic details, or the capacity of spermatozoa to interact with the environment, in terms of membrane reactivity, unless a battery of tests is used. Neither can they measure whether the genomic message spermatozoa deliver to the gamete counterpart during fertilization is intact enough to warrant the development of the early embryo. Last but not least, most routine semen evaluations include small subsamples (often tested in different assays, so that the same spermatozoon is not evaluated simultaneously by the different tests) of a large, heterogeneous number of spermatozoa in the ejaculate. This implies that the results obtained have an inherent large variability, thus calling for the analyses of larger sperm numbers. ${ }^{13}$ It is important to remember that for a given attribute of a cell only a small amount of an attribute might be needed for that cell to function correctly; for another attribute high values might be necessary. Further, it is illogical to assume that all cells of a certain type do their tasks the same way. ${ }^{17}$

As already indicated, another major point during semen evaluation is the varying resilience of ejaculated spermatozoa to sustain current and future handling procedures, including extension or reconcentration, cooling, freezing and thawing, high-speed sorting, selection, etc., 
to which ejaculated spermatozoa are nowadays subjected to for use in assisted reproductive technologies, such as artificial insemination or in vitro fertilization of chilled, frozen-thawed or sexed semen. Markers that can determine how extensive the damages are, and that can monitor their occurrence can be used for a quick, detailed analyses of a large number of spermatozoa of a given sample. ${ }^{10,18}$

Continuous innovation of new fluorescent stains and techniques has facilitated this development. Moreover, with the simplification of the instrumentation, flow cytometry (FC) is now being introduced into handling of semen for $\mathrm{AI}$ and even into routine andrological diagnostics.

The present review summarizes the state of the art regarding FC applied to animal andrology, albeit keeping an open comparative intent. It critically evaluates the present and future capabilities of FC for the diagnostics of potential fertility and for the development of current reproductive technologies such as sperm freezing, sperm selection and sperm sorting.

\section{PRINCIPLES OF FC AND COMPARISON TO OTHER CONVENTIONAL TECHNIQUES TO EXPLORE SPERM STRUCTURE AND FUNCTION}

An FC is an instrument that can measure physical, as well as multicolor fluorescence properties of particles of cells flowing in a flowing stream. ${ }^{19}$ An FC is basically composed of four main systems, fluidics, optics, electronics and software handling, so that the cell suspension flows through a tubular system, it is exposed to laser (or mercury arc lamp in some older instruments) illumination at particular spots, and the recorded emissions from the cells as a result of this illumination is digitized and computer-handled to provide understandable results.

A fluid that is moving under a laminar flow specifies the movement and velocities that cells have when passing across the detector. During this transport, cell properties like fluorescence, absorbance and light scattering can be detected, making use of one or several illumination sources, which might differently excite uploaded markers. In this way, FC detects labeling by multiple fluorochromes associated with individual spermatozoa, so that more than one sperm attribute can be assessed simultaneously, increasing our capacity to correlate these attributes to, for instance, potential fertilizing capacity. Moreover, it makes possible to acquire data from different subpopulations within a sample, thus evaluating heterogeneous populations in different states of activation. Thus, the analysis becomes objective, has a high level of experimental repeatability and has the advantage of being able to work with either small or large sample sizes.

FCs can be broadly classified as analytical (or bench-top), sorter and others with miscellaneous functions. Analytical FCs are used solely for the analysis of cells or other particles, while FC sorters have the additional feature that they are able to, based on the results of the analysis, physically isolate the cells or particles of interest. Sorter FC types can either maintain a continuous fluid or split it into droplets after detector analysis. Fluidic sorters better handle biohazardous samples than the droplet sorters, while the latter are used, for instance, to separate spermatozoa by chromosomal sex.

There is a number of commercial FCs developed for specific requirements. These may be broadly function-grouped as the following.

\section{Analytical}

The most commonly used FCs are sold by Partec (Münster, Germany), Beckman Coulter (Brea, CA, USA), Millipore (Billerica, MA, USA), Accuri (Ann Arbor, MI, USA) and BD Biosciences (Franklin Lakes, NJ, USA).

\section{Sorter type}

Partec (PA-II and PAS-III), Beckman Coulter (MoFlo XDP and EPICS ALTRA), BD Biosciences (BD FACSAria, BD FACS Vantage and BD Influx) sells sorter type FCs.

\section{Others}

FCs with new functions are becoming available; Luminex Corporation (Austin, TX, USA) is dedicated to multiple analysis by suspension arrays (the Flexmap3D and Luminex 100/200 instruments), where very small sample volumes can be assayed in a single microplate well. It facilitates nucleic acid assays, receptor-ligand assays, immunoassays and other enzymatic assays. CompuCyte (Beckman Coulter) is a laser scanning solid cytometer which can analyze solid-phase samples together with tissue sections, cancer tissue imprints and cytology smears. This FC is capable to manage high amounts of cell and tissue specimens in a solid substrate analysis. CytoBuoy (Woerden, The Netherlands) is, together with CytoSense, a simplified method (albeit a very expensive one, thus far) to recognize spermatozoa from other cells and debris by shape only. This can, above traditional FC, produce complete signal courses of the measured emission of each particle. It is a portable FC suitable for submerged in situ studies up to $200 \mathrm{~m}$ depth together with silico-imaging and video imaging, mainly applicable for phytoplankton research. The newest BD FACS Array (BD Biosciences) technology can easily assess cell signaling, cell surface staining and multiplexed bead assay. It is best suited for protein analysis in cell biology, immunology and more specifically for proteomics studies.

\section{APPLICATION OF FC FOR ASSESSMENT OF SPERM ATTRIBUTES}

\section{Enumerating sperm}

Total sperm per ejaculate and total sperm per straw are both important. Moreover, with breeding companies decreasing sperm numbers in the AI doses, accurately accounting how many spermatozoa are inseminated is of utmost importance. The issue of time since collection is also important, since total sperm per ejaculate per hour since latest collection can give information about productivity of the testes, if that time is appropriately short. ${ }^{20}$ Total sperm per straw marks that the insemination dose is as advertised and it is likely to maximize fertilizing potential for that bull if little is known about his response to decreasing number of sperm/insemination. However, to precisely determine the number of spermatozoa in a suspension volume is difficult, unless time-consuming manual chamber counting is done. FC of fluorescence-loaded samples appears as a good alternative to determine sperm total sperm count since FC can discriminate between cells and debris (even considering other cells than spermatozoa) yet counting high cell numbers, thus decreasing variation. For instance, similar results for total sperm count between FC and hemocytometry have been recorded for a number of species. ${ }^{21}$ However, the inherent costs of FC have to be considered. Moreover, FC often overestimates the proportion of viable unstained spermatozoa while underestimating that of the damaged subpopulation. ${ }^{22}$ We will discuss this phenomenon later in this review. Using fluorescent microbeads, total sperm counts were assessed by FC, simultaneously with other sperm analyses (Figure $\mathbf{1}^{23-25}$ ). However, as the beads can introduce another source of variation, alternative FC cell counting methods, like true volumetric counting, were developed. ${ }^{26}$

\section{Sperm intactness}

Viability of spermatozoa. Sperm viability is a convenient, yet imprecise term, because there is no clear demarcation between a living or dead 
sperm. It is a key determinant of sperm quality and a prerequisite for successful fertilization, becoming more and more important when low sperm numbers are used for AI. Although a motile spermatozoon could be defined as viable, the term 'viable spermatozoon' is often linked to an intact plasma membrane, since the plasmalemma is pivotal for sperm interactions with other cells and their environment. Therefore, most viability assay kits just evaluate whether the plasmalemma is intact or not, by using impermeable dyes (those that cannot penetrate an intact membrane) alternatively penetrating dyes (to depict those cells with eroded plasmalemma), or a combination, a matter that shall be described in detail later. Which dye is used can significantly influence the results. ${ }^{27}$ Sperm 'viability' can be assessed by numerous methods, some manual and other automated, and not only directed to the plasmalemma. Some of them are slow, assess too few spermatozoa and are thus poorly repeatable. The reader is advised to see the reviews by Rodriguez-Martinez and Barth ${ }^{11}$ or RodriguezMartinez ${ }^{13}$ for a summary of these methods while studying the spermiogram.

Plasma membrane integrity. The sperm membrane is directly or indirectly related with many sperm functions, warranting the capability of the cell to maintain homeostasis and depict motility and the capacity to interact with the environment, including the lining epithelium of the female genital tract or the oocyte-cumulus cell complex. ${ }^{7}$ Although the sperm plasma membrane covers the entire cell, it consists of several distinct membrane compartments, like the one that covers the outer acrosome membrane, one that covers the post acrosome portion of the sperm head down to the annulus, and lastly another one covering the principal piece and the rest of the tail. The first fluorescent probes applied to evaluate plasma membrane integrity were fluorescein diacetate ${ }^{28}$ and carboxyfluorescein diacetate. ${ }^{29}$ These dyes are non-fluorescent, but converted to fluorescent derivatives by intracellular esterase enzymes, and trapped by the intact plasma membrane, resulting in a fluorescing cell.

The most commonly used combination of dyes used for membrane integrity checks is SYBR-14/propidium iodide (PI) (Figure 2). In this combined stain, the nuclei of viable spermatozoa fluoresce green, while those with eroded plasmalemma are counterstained red, including a moribund cell subpopulation (green-red). Propidium iodide is normally used as the viability probe of choice in FC as this supravital stain rapidly penetrates non-viable spermatozoa when their plasma membrane is disrupted. ${ }^{30}$

This FC procedures (available as a live/dead kit from Invitrogen (Carlsbad, CA, USA)) have been successfully applied for many species, as human, ${ }^{31}$ bovine, ${ }^{32}$ porcine,${ }^{13,31,32}$ ovine, ${ }^{31}$ Lagomorpha, ${ }^{31}$ murine ${ }^{31,33}$ avian, ${ }^{34,35}$ honey bees ${ }^{36,37}$ and fish. ${ }^{38}$ Furthermore, it is able to simultaneously evaluate sperm cell viability together with some other attributes, e.g., in combination with fluorescently labeled plant lectins for simultaneous assessment of plasma membrane and acrosome integrity. ${ }^{39}$ The main advantage of this dye combination is that both fluorochromes have the same intracellular target (DNA); however, it means its main weakness as well: since most DNA is found in the sperm head (and less in the mid-piece in the mitochondria), the assay indicates the integrity of the plasma membrane of the head domain only. Moreover, the probe mentioned above will not assess the integrity of the plasmalemma covering neither the acrosome, the mid-piece nor the rest of the tail.

Assessing sperm membrane permeability and stability. As mentioned above, the intactness of the sperm plasma membrane is of utmost importance for cell integrity and function. ${ }^{40}$ Membrane stability and permeability are two closely interlinked functionalities; thus, evaluation of membrane permeability elucidates its organization, ${ }^{41}$ and its capability to undergo biophysical changes such water and the movement of cryoprotectant agents during cryopreservation. ${ }^{18,42}$ Cryopreservation causes irreversible damage to the plasma membrane, leading to cell death in a large number of spermatozoa. ${ }^{43}$ Thus, it is important to know the permeability coefficient of the cells to cryoprotectant agents, as well as their effect on the hydraulic conductivity of the membrane. Different methods, like Coulter counter, electron microscopy, stopped-flow fluorometry and differential scanning calorimetry, have been used for years to evaluate membrane permeability. ${ }^{44}$ Differences between cell populations in their uptake of Hoechst 33342 due to altered membrane permeability have also been studied. ${ }^{45}$ New fluorescent probes (SNARF-1, YO-PRO-1 and ethidium homodimer) for membrane permeability have improved the value of using $\mathrm{FC}^{42}$ for this purpose. YO-PRO-1 is an impermeable membrane probe that can leak in after destabilization of the membrane, as a result of silencing of a multidrug transporter involved in transporting it out of intact cells. Thus, use of YO-PRO-1 is a useful tool for detecting early membrane permeability. ${ }^{46}$ The three probes are easily distinguished both in FC and in fluorescence microscopy.

Annexin $\mathrm{V}$ is a calcium-dependent probe that has recently being used for tracking externalization of phosphatidylserine (PS) in the sperm membrane. Since PS is normally located exclusively at the inner face of the lipid bilayer, such externalization monitors early changes in membrane stability and intactness, detectable earlier than when PI is used, for instance (Figure 3). Combining SNARF-1, YO-PRO-1 and ethidium homodimer offers some advantages over the Annexin V/PI assay. Whereas in the Annexin V/PI assay, there is always an unstained subpopulation, the triple stain labels all the spermatozoa in the sample. The subpopulation of live cells using the new triple staining concurs with the subpopulation of live cells using the well-validated Annexin V/PI assay. Also, the percentage of early damaged spermatozoa was higher with the Annexin V/PI assay. This might reflect an increase in membrane permeability, preceding the transposition of PS during an evolving cryodamage. However, it can also be, in a yet to be determined physiological change, a very early step, while changes in cell volume regulation and movement of ions occur, during the initiation of apoptosis ${ }^{47}$ or cryoinjury. ${ }^{48}$ In addition, an earlier inactivation of enzymes involved in maintaining membrane asymmetry than those involved in transporting amphipathic small molecules like YO-PRO-1 might explain this fact.

The FC evaluation of plasma membrane integrity used many fluorescent probes and new probes are emerging rapidly. The Annexin V/PI assay works for tracking PS exposure in cryopreserved samples, but due to the presence of cell debris and egg yolk particles, this probe combination might overestimate the unstained subpopulation when using FC for detection. Considering this limitation, use of YO-PRO-1 in combination with SNARF-1 and ethidium homodimer has been tested in cryopreserved boar spermatozoa with good correlation with Annexin V/PI as a result. ${ }^{49}$ Another alternative for assessing early changes was to use another triple fluorochrome combination of Merocyanine 540, YO-PRO-1 and Hoechst $33342,{ }^{50}$ proving effective for several species. ${ }^{51}$

Acrosome integrity. The acrosome is a membrane-enclosed structure covering the anterior part of the sperm nucleus. Powerful hydrolyzing enzymes belong to that structure, which is a basic feature of the sperm head of all mammals. ${ }^{52}$ Acrosomal integrity is a prerequisite for 


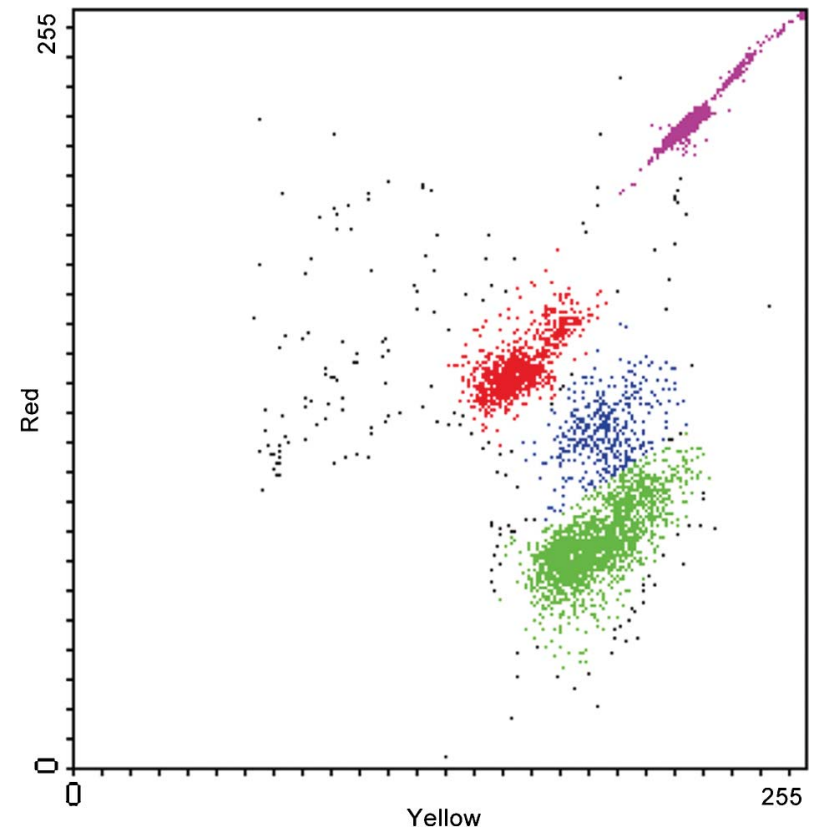

Figure 1 Color dot plot representing the simultaneous evaluation of viability (SYBR 141/PI staining) and cell concentration. Viable spermatozoa are indicated by green color, dead ones are indicated by red color and dying spermatozoa are indicated by blue color. Fluorescent microbeads are indicated by magenta color. $\mathrm{Pl}$, propidium iodide.

fertilization, ${ }^{12}$ essential for sperm penetration of the zona pellucida. Biologically, the plasma membrane and the outer acrosome membrane fuse and vesicate during the acrosome reaction when activated by sperm binding to the zona pellucida. Acrosome intactness is traditionally examined in vitro using phase-contrast microscopy or differential interference-contrast microscopy on unstained or stained samples for light microscopy. ${ }^{2}$ Fluorescent microscopy-based staining are chlortetracycline staining, ${ }^{53,54}$ paramagnetic beads, ${ }^{55}$ quinacrine,${ }^{56}$ fluorescein

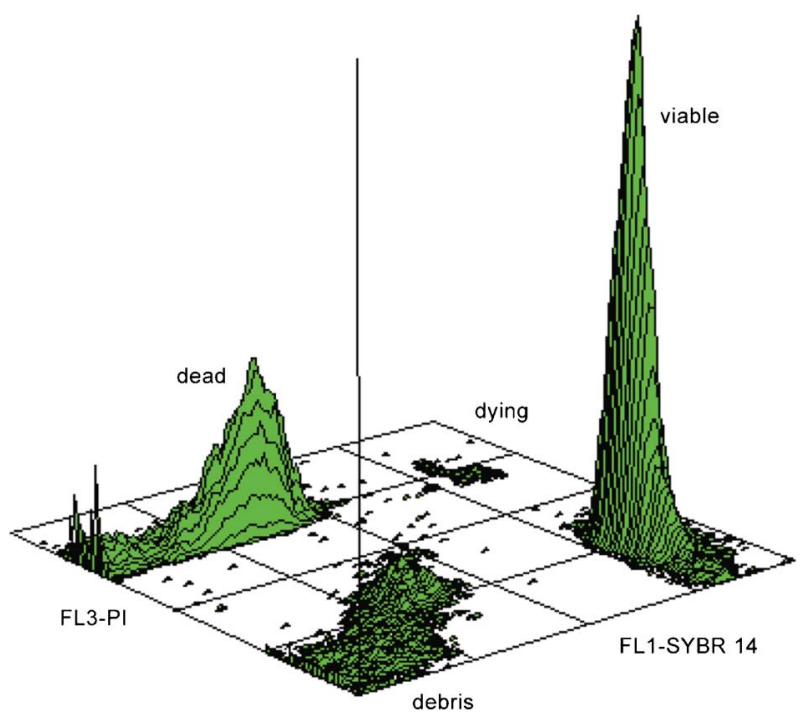

Figure 2 Viability evaluation by SYBR 14/PI labeling. Three-dimensional contour plot shows distinct peaks for viable and dead spermatozoa; moreover, dying spermatozoa and cell debris can be easily recognized as well. PI, propidium iodide.

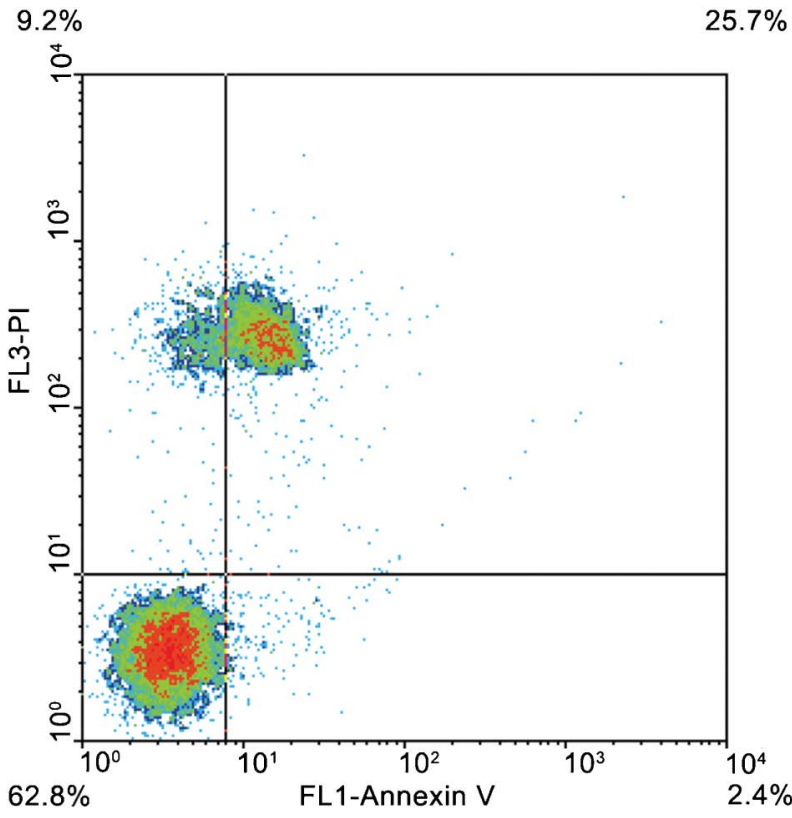

Figure 3 Annexin V/PI labeling. Density plot shows non-altered spermatozoa (lower left quadrant), PI-negative spermatozoa with exposed PS (lower right quadrant), PI-positive spermatozoa without exposed PS (upper left quadrant) and PI-positive spermatozoa with exposed PS (upper right quadrant). PI, propidium iodide; PS, phosphatidylserine.

isothiocyanate-labeled Pisum sativum agglutinin (FITC-PSA) ${ }^{57}$ and FITC-concanavalin A (FITC-ConA) ${ }^{58,59}$ Electron microscopic studies have demonstrated the ultrastructural morphology of acrosomes with the staining patterns of spermatozoa after labeling with the antibodies by Pietrobon et al. ${ }^{60}$ Due to high costs and need for trained personnel, such approach is rarely used and suitable only for research purpose. Although epifluorescence microscopy is being used, Peña et al. ${ }^{61}$ observed that it was less precise for detecting the percentage of spermatozoa with damaged acrosomes compared to FC.

The FC can advantageously be used instead of epifluorescent microscopy, ${ }^{10}$ allowing determination of acrosome reaction and its temporal occurrence, and the examination of large sperm numbers. The most commonly used probes are plant lectins labeled with a fluorescent agent (usually FITC), most commonly PSA or peanut agglutinin (PNA). PSA is a lectin from the pea plant that binds to mannose and galactose moieties of the acrosomal matrix. As PSA cannot penetrate an intact acrosomal membrane, only acrosomereacted or damaged spermatozoa will stain. ${ }^{62}$ Arachis hypogaea agglutinin (PNA) is a lectin from the peanut plant which is believed to display less non-specific binding to other areas of the spermatozoon, leading some workers to favor this over PSA ${ }^{63}$ and it is the lectin of choice when evaluating sperm extended in egg yolk-containing media, as PSA has a nonspecific binding affinity to egg yolk ${ }^{64}$ and several nonspecific binding sites on the sperm cell surface. ${ }^{63}$ Carver-Ward et al. ${ }^{65}$ proposed that PNA is the most reliable lectin compared to PSA and ConA. Only PNA gives a specific comparison between unreacted and reacted sperm, and the differences between the two markers are merely a matter of magnitude. Petrunkina et al. ${ }^{66}$ observed that FITC-PNA binds to the outer acrosomal membrane, ${ }^{67}$ so that it can better monitor acrosomal integrity. One of the frequently used fluorochrome combinations for the simultaneous assessment of plasma membrane integrity and acrosomal integrity are FITC-PSA and PI. ${ }^{61}$ This double staining for membrane integrity and acrosomal 
integrity is relatively reliable for fresh and in vitro capacitated sperm. ${ }^{68}$ Problems can arise when frozen-thawed spermatozoa are analyzed. Egg yolk particles from the extender have low fluorescence and, therefore, can be assessed as live acrosome-intact sperm using the PI/FITCPSA double-labeling method. However, it is yet argued that lectins do not specifically bind to the acrosome region ${ }^{69}$ and that other binding sites can be easily distinguished by epifluorescence microscopy, whereas FC only identifies one signal from the entire spermatozoon. A newly developed triple staining (SYBR-14, phycoerythrin-conjugated PNA and PI; Figure 4) procedure was developed and in our hand was found as an efficient method for evaluating acrosomal integrity together with viability. ${ }^{39,70}$ This combination labels every DNAcontaining event and the colors of the fluoroprobes fit to the standard filter set of most commercial FCs. The phycoerythrin-conjugated PNA can also be prepared in the laboratory. ${ }^{71}$

\section{Mitochondrial status}

Mitochondria, located in the sperm mid-piece generate a major part of the ATP required for sperm metabolism, membrane function and motility, alongside with anaerobic glycolysis in the cytoplasm. ${ }^{19,72-74}$ Besides, mitochondria are the coordinators of apoptosis mechanisms in a number of cell systems, ${ }^{75,76}$ and they are involved in sperm maturation ${ }^{72}$ and protection against damage induced by cryopreservation. ${ }^{74}$ Recently mitochondrial proteins were found to be involved in the capacitation-dependent tyrosine phosphorylation in spermatozoa. ${ }^{77}$

There are approximately 100 mitochondria in the mid-piece of the spermatozoon, depending on the species. ${ }^{78}$ Most of these dyes applied in the evaluation of mitochondrial status work by diffusing into living cells and accumulating in mitochondria. The most widely used mitochondrial-specific probe, rhodamine 123 (R123), is a cationic compound that accumulates in the mitochondria as a function of transmembrane potential. ${ }^{79}$ It was historically applied to spermatozoa in combination with ethidium bromide. ${ }^{80}$ The R123 accumulates in the mitochondria and fluoresces green, the fluorescence intensity depends on total amount of functioning mitochondria. Spermatozoa with damaged membranes are usually identified by the uptake of ethidium bromide or PI, to discriminate between those living and dead. ${ }^{80}$ Unfortunately, this stain does not differentiate between mitochondria that exhibit high respiratory rates. When mitochondrial membrane potential is lost, R123 is washed out of the cells. The main weakness of R123 is that it has low sensitivity and mitochondria have several energy-independent binding sites. ${ }^{81}$

The mitochondrial probe MitoTracker Green ${ }^{82}$ is non-fluorescent in aqueous solution, but fluoresces green upon accumulation in the mitochondria regardless of mitochondrial membrane potential. ${ }^{83}$ The mitochondrial stain 5,5',6,6' -tetrachloro-1,1',3,3' -tetraethylbenzimidazolylcarbocyanine iodide (JC-1; Figure 5) that exists as a monomer at low concentration yielding green does permit a distinction to be made between spermatozoa with poorly and highly functional mitochondria. ${ }^{84}$ Martinez-Pastor et al. ${ }^{85}$ observed some relationship between JC-1 staining and motility, although correlation with motility is regulated by many factors. In highly functional mitochondria, the concentration of JC-1 inside the mitochondria increases and the stain forms aggregates that fluoresce orange. When human spermatozoa were divided into high, moderate and low mitochondrial potential groups, based on JC-1 fluorescence, the in vitro fertilization rates were higher in the high potential group than in the low potential group. ${ }^{86}$ JC-1 has also been used successfully to measure mitochondrial function using fluorometry. ${ }^{87}$ The main weakness of JC-1 is that two fluorescent detectors are needed to evaluate one sperm attribute; therefore, it is less applicable in multicolor FC experiments. Moreover, Garner and Thomas ${ }^{84}$ found the presence of aggregates only marginally detectable after cryopreservation. They hypothesized that cryopreserved sperm cells have damaged metabolic capacity, probably due to glycerol. We developed an alternative labeling technique, using MitoTracker Deep Red, ${ }^{78}$ which needs only one detector to identify spermatozoa with high and low mitochondrial membrane potential (Figure 6). Unfortunately, the spectral properties of this particular dye do not fit to the smaller bench top FCs equipped with a 488-nm laser source only.

There are some other mitochondrial stains like 3,3'-dihexyloxacarbocyanine iodide and 2-(4-(dimethylamino)styryl)- $N$-ethylpyridinium iodide which stain mitochondria of living cells that ought to be tested in andrology. A recent study showed accumulation of cationic lipophilic probe 3,3'-dihexyloxacarbocyanine iodide in combination with PI could assess mitochondrial membrane potential effectively in pig spermatozoa. ${ }^{88}$ Other studies indicate, however, that 3,3'-dihexyloxacarbocyanine iodide is not specific to mitochondrial membrane potential. ${ }^{89}$

\section{Chromatin intactness}

Evaluation of sperm DNA integrity is of utmost importance owing to early embryo development depending on its normality. ${ }^{12,13}$ Although sperm DNA is packed in a highly compacted and stable form, ${ }^{90}$ chromatin abnormalities and DNA damage exist, derived from either premeiotic testicular insults, during spermiogenesis, when DNA is packed or during further chromatin building (protamine dominance) during epididymal maturation. ${ }^{91-93}$ Alternatively, it could be the result of free radical-induced damage ${ }^{94}$ or a consequence of apoptosis, in some species. ${ }^{95}$ Sperm DNA fragmentation can be assessed with terminal deoxynucleotidyl transferase-mediated dUTP nick end labeling (TUNEL) assay, which can identify DNA strand breaks with modified nucleotides. These incorporated labeled nucleotides can be detected in spermatozoa by FC, fluorescence microscopy or light microscopy. ${ }^{96}$ TUNEL can simultaneously detect single- and double-strand breaks. By TUNEL the degree of DNA damage within a cell cannot be quantified, which only reveals the number of cells within a population with DNA damage An advantage of the TUNEL assay is its application in FC, ${ }^{97}$ although Domínguez-Fandos et al. ${ }^{98}$ found 2.6 times greater sperm damage by FC than that of fluorescent microscopy, thus suggesting that it may overestimate damage. Chromomycin A3 (CMA3) is a fluorochrome that detects protamine deficiency in loosely packed chromatin, which is correlated to the extent of nicked DNA. ${ }^{10}$ The CMA3 is a useful tool to assess the packaging quality of sperm chromatin and allow indirect visualization of protamine deficiency. Traditionally fluorescence microscopy is being used to evaluate DNA integrity by CMA3, but recently it was reported that this CMA3 can evaluate DNA integrity in human spermatozoa though fixation, and number of sperm or duration of exposure to CMA3 might affect efficacy of FC outcome. ${ }^{99}$

The sperm chromatin structure assay (SCSA; Figure 7) is a technique originally developed by Evenson et al. ${ }^{100}$ in which the extent of DNA denaturation following acid treatment is determined by measuring the metachromatic shift from green fluorescence to red fluorescence for acridine orange, thus determining the ratio between single- and double-stranded DNA in each spermatozoon. Consequently the native sperm DNA is stained green, while the denatured (because it was already either denatured by the time the acid exposure was issued or broken by the procedure) DNA is stained with orange. In FC, sperm containing greater red to green ratios are exhibiting more 


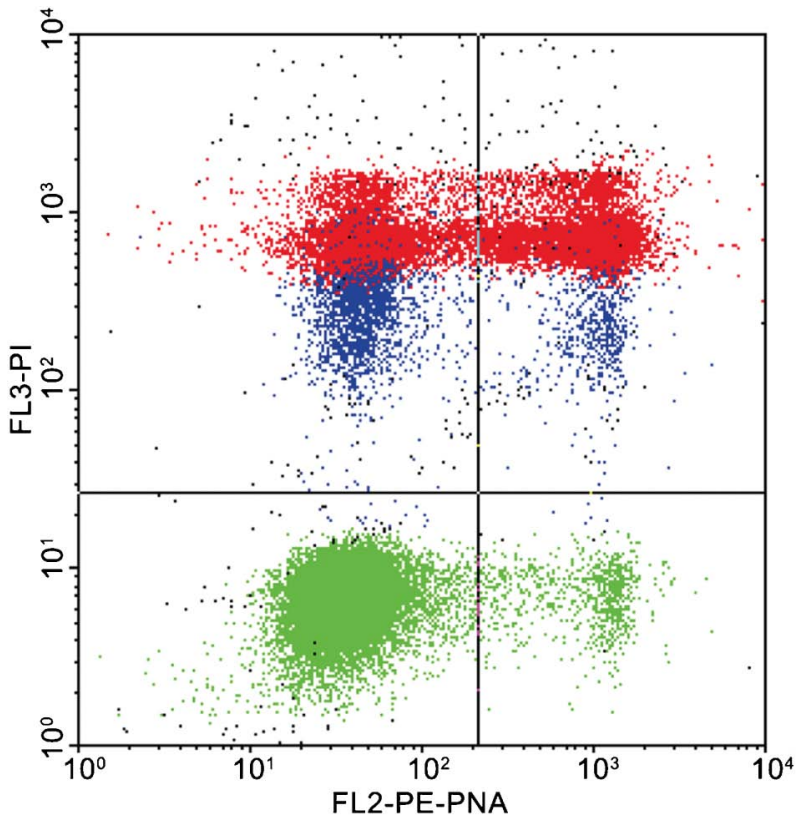

Figure 4 Simultaneous evaluation of viability and acrosome integrity (SYBR 14/ PE-PNA/PI labeling). Color dot plot shows viable, acrosome-intact (lower left quadrant), viable, acrosome-ruptured (lower right quadrant), dead, acrosome intact (upper left quadrant) and dead, acrosome-ruptured spermatozoa (upper right quadrant). Green color indicates viable cells, red indicates dead ones, blue color indicates dying spermatozoa (evaluated as dead). PE, phycoerythrin; PI, propidium iodide; PNA, peanut agglutinin.

DNA denaturation than that of spermatozoa exhibiting lesser red to green ratios. ${ }^{101}$ One benefit of SCSA over other methods that evaluate DNA integrity is that the procedure is relatively easy, quick, and

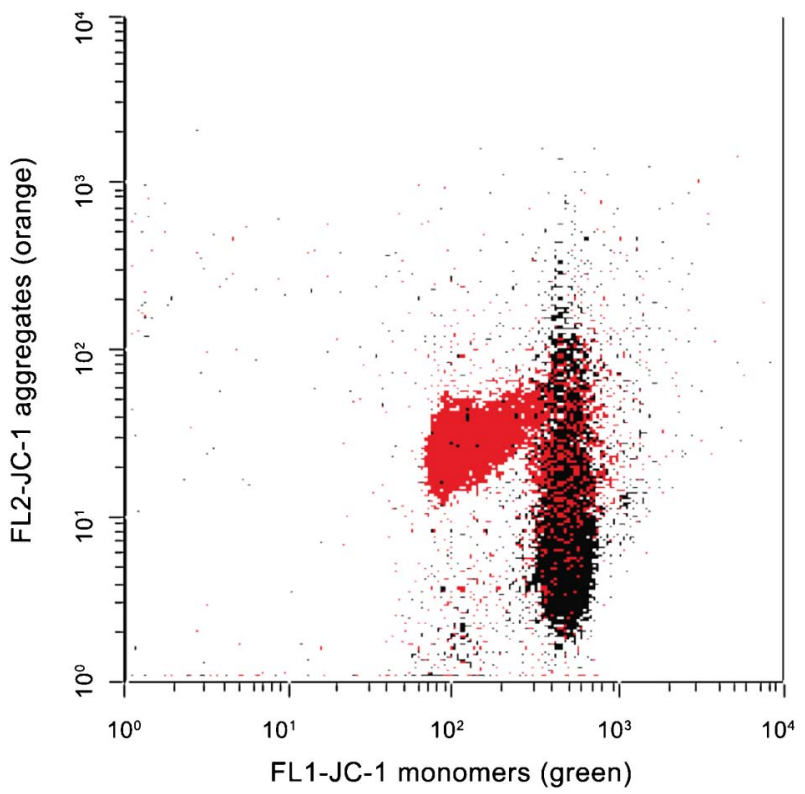

Figure 5 Mitochondrial membrane potential, evaluated by JC-1. Color dot plot shows a raw semen sample before (red) and after (black) freeze killing (plunging the semen aliquot into liquid nitrogen). List mode files were merged with FCSExpress software (version 3.0; De Novo Software, Los Angeles, CA, USA). JC-1, 5,5',6,6'-tetrachloro-1,1',3,3'-tetraethylbenzimidazolyl-carbocyanine iodide.

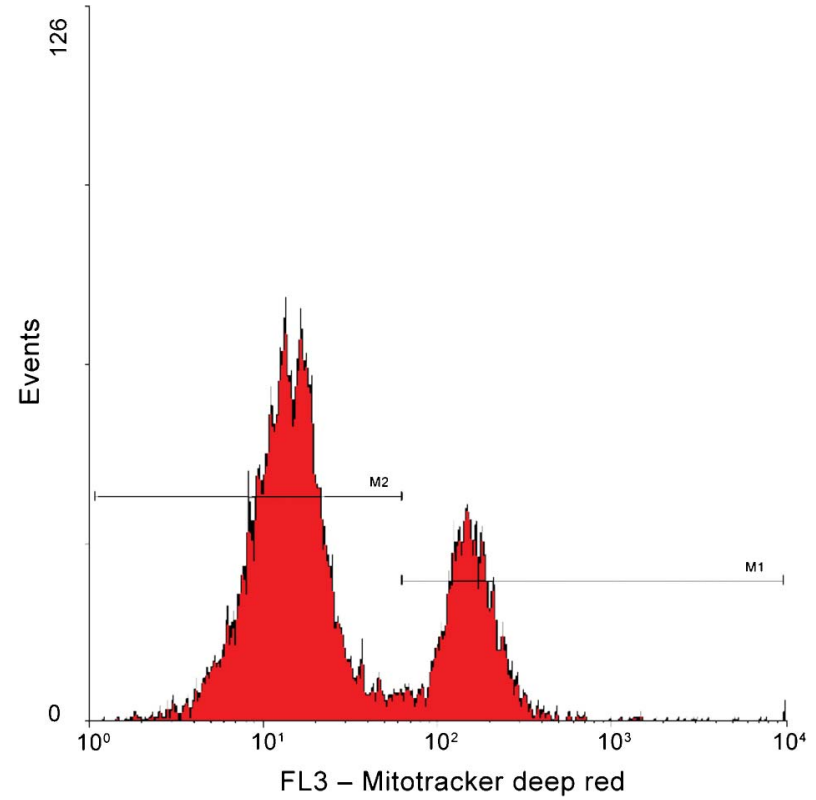

Figure 6 Mitochondrial membrane potential evaluation by Mitotracker Deep Red. Histogram shows spermatozoa with high (marker M1) and low (marker M2) mitochondrial membrane potential.

thousands of sperm can be evaluated objectively. The SCSA has also been successfully used to check gamete quality after cell manipulation. ${ }^{102}$ The most important parameter revealed by SCSA is the DNA fragmentation index, which assesses the percentage of spermatozoa showing susceptibility of DNA to the acid induced denaturation in situ. Unfortunately, the method does not really measure the pure population of spermatozoa really having damaged DNA, which is to

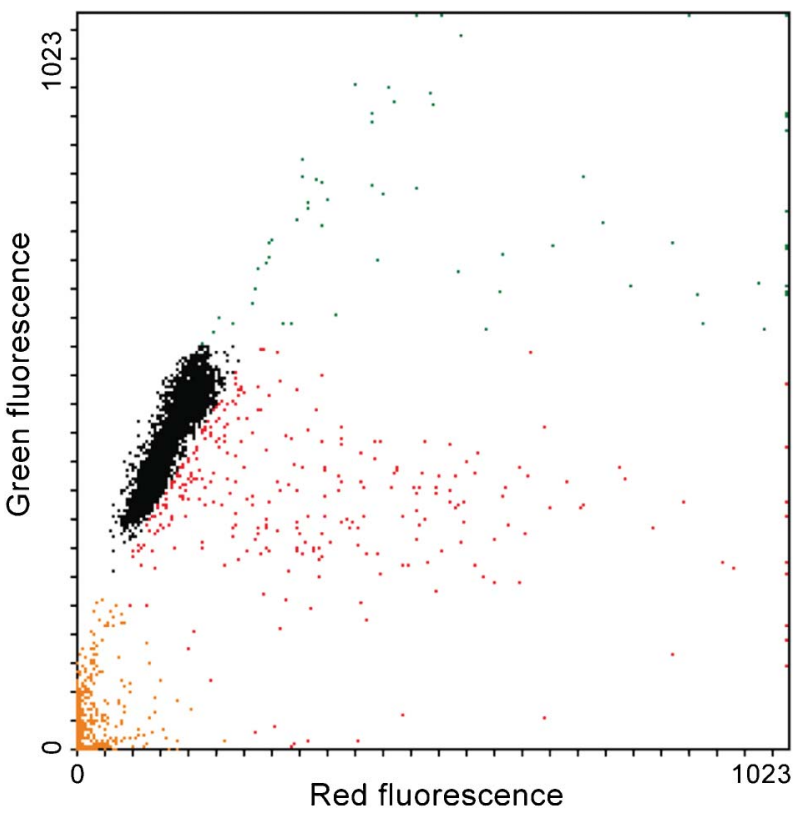

Figure 7 Sperm chromatin analysis by acridine orange staining. Intact spermatozoa are indicated by black color, cells with increased amount of single-stranded DNA (indicating DNA damage) are indicated by red color and spermatozoa with immature chromatin are indicated by green color. Cell debris is indicated by orange color and gated out during analysis. 
be considered a relevant drawback. In humans, and only under certain conditions of assessment of fertility (assisted reproductive technology procedures), males with semen samples with more that $30 \%$ DNA fragmentation index were considered unable of establishing pregnancy. ${ }^{103}$ In animals, where SCSA is the most widespread method to assess chromatin integrity among domestic animals, ${ }^{104-106}$ particularly related to processed semen (including storage and cryopreservation), there is a relationship between chromatin damage and fertility, but thresholds are far from established with certainty. ${ }^{11}$ Another parameter indicated by SCSA is the ratio of spermatozoa with high green fluorescence. These spermatozoa have less compacted chromatin and consequently higher green fluorescence and ought to be considered immature. ${ }^{107}$ In animals not bred for fertility, e.g. horses, there is considerable variation in DNA fragmentation index, ${ }^{106}$ while the variation is minimal in breeding pigs. ${ }^{108}$

\section{FC TO ASSESS SPERM FUNCTIONALITY}

\section{Changes induced during capacitation}

Capacitation is an important, but rather incompletely understood phenomenon that a spermatozoon undergoes before it can fertilize the oocyte. It primarily takes place in the oviduct ${ }^{57}$ when various cellular changes such as an increase in membrane fluidity due to lipid modifications, an influx of calcium to the sperm perinuclear and neck regions and flagellum, the generation of controlled amounts of reactive oxygen species, as well as the phosphorylation of protein residues, occur in a concerted manner. ${ }^{109-111}$ Therefore, there is no general agreement regarding which assay is most appropriate to discern between capacitated and uncapacitated spermatozoa. One of the most widely used methods to map these differences is the chlortetracycline assay using fluorescence microscopy. This fluorescent antibiotic will detect enhanced fluorescence over the segments of the membrane where $\mathrm{Ca}^{2+}$ accumulates, and depict different binding patterns on the sperm head, believed to reflect different stages of the capacitation process. ${ }^{53}$ Though chlortetracycline is empirically accepted, it is laborious to use and its working mechanism remains still scientifically unexplained.

Early stages of sperm capacitation can be measured by loading spermatozoa with the lipid dye Merocyanine 540. ${ }^{112}$ The fluorescence observed by the FC is depending on the degree of lipid disorder. ${ }^{40}$ Merocyanine 540 is a hydrophobic dye, which can monitor membrane integrity especially scrambling of phospholipids when coupled with YO-PRO-1 and Hoechst 33342 (Figure $\mathbf{8}^{50}$ ). Bicarbonate has the potential to increase Merocyanine fluorescence rapidly, which ultimately indicates that phospholipid packing of the plasma membrane becomes disordered by this ion. Likewise, calcium-dependent binding of Annexin V is able to detect capacitation-related changes in membrane architecture, especially the dislocation of PS in the lipid membrane leaflet, thus indicating early subtle changes in membrane integrity during capacitation. ${ }^{113}$ One study, however, showed that both Merocyanine 540 and Annexin V indicate early plasma membrane degeneration and not capacitation—at least in human sperm. ${ }^{114}$

Calcium influx is crucial for the onset of protein tyrosine phosphorylation. Displacement of calcium in the head plasmalemma occurs during the latter part of capacitation. ${ }^{13}$ Indo- 1 acetoxymethylester ${ }^{115}$ and Fluo ${ }^{116}$ are being used for FC determination of calcium. Recently, a FC determination of dynamic quantification of the protein tyrosine phosphorylation in the sperm membrane protein during the capacitation was ascertained. ${ }^{116}$ The antiphosphotyrosine antibody can quantify tyrosine phosphorylation in boar spermatozoa using FC, thus waiving the tiresome traditional evaluations with western blotting.
The FC will quantitate subpopulations within samples and estimate global phosphorylation in the entire spermatozoon, which might better correlate with the capacitation process, since FC most likely solely evaluates the process in the surface of live spermatozoa. ${ }^{117}$

However, when using FC in sperm plasma membrane physiology studies, especially to investigate early membrane changes, one should be careful to avoid introducing labeling artifacts. ${ }^{118}$

\section{Apoptotic-like changes}

Apoptosis, 'programmed cell death', delimits a sequence of events, which leads to the destruction of cells without releasing harmful substances into its surrounding area. Apoptosis plays a distinct role in the development and maintenance of health by eliminating old and unnecessary cells, as well as unhealthy cells. Apoptosis markers have been detected in spermatozoa of many species, but the role of these markers is probably not yet elucidated completely. ${ }^{49,119-122}$ Changes of sperm membrane permeability have been considered as a typical event of apoptosis in many studies. Since cryopreservation, freezing and thawing cause cryodamage, and presumably even apoptotic-like changes, ${ }^{123}$ apoptotic markers can be good tools for forecasting semen freezability and cellular damage occur during cryopreservation, albeit not necessarily indicting apoptosis really occurs. ${ }^{124}$ The combination of Annexin V with PI is able to simultaneously determine apoptosislike changes and spermatozoa with compromised plasma membrane. This combination can detect four categories of sperm populations: live, live early 'apoptotic', dead and late 'apoptotic', and late 'necrotic' cells. ${ }^{125}$ The APO-BRDU kit to conduct TUNEL assay for determination of DNA fragmentation was found more effective than the Annexin/PI in bull spermatozoa, although detection of necrotic spermatozoa cannot be performed by the APO-BRDU kit. The TUNEL assay measures changes at the later stage, while Annexin V/PI measure early sperm apoptosis-like changes. Poly(ADP-ribose) polymerase is a nuclear protein recently being used as an effective apoptosis detector. During apoptosis, poly(ADP-ribose) polymerase cleavage occurs which is the classical characteristic of apoptosis, ${ }^{126}$ and it has been detected in human spermatozoa. ${ }^{127}$ The sequence of sperm death might be loss of mitochondrial membrane potential, membrane change (YO-PRO- $1^{+}$and $\mathrm{PI}^{-}$) and membrane damage $\left(\mathrm{PI}^{+}\right)$. However, it was suggested that apoptotic markers like caspase activation and YO-PRO-1 staining might happen only in a specific subpopulation of spermatozoa in red deer, ${ }^{128}$ and perhaps even reflect methodological deviations.

Caspases, a specific group of cysteine proteases with strong preference for aspartyl residues, is considered to be involved in apoptotic degenerative processes as execution agents common to almost all cell types investigated. ${ }^{129}$ Still the question is: does apoptosis occur in spermatozoa or only in those species where remnants of cytoplasm are largely available (usually the case for human spermatozoa and for stallion spermatozoa and somewhat for dog spermatozoa, where the amount of cytoplasmic droplets is significant. Nonetheless, Weil et al. ${ }^{130}$ did not find any evidence for the involvement of caspases in mouse sperm normal death. Furthermore, it was stated that there is no reason of occurring apoptosis in spermatozoa. ${ }^{122}$ However, it was evident that caspases were present in the restricted site for apoptosis in spermatozoa, which resulted in poor sperm quality. ${ }^{131}$

\section{Sperm head decondensation during fertilization}

During mammalian spermiogenesis, the sperm chromatin undergoes a step-by-step condensation and packaging mainly characterized by replacement of histones with protamines and the formation of $\mathrm{S}-\mathrm{S}$ and 
$\mathrm{S}-\mathrm{Zn}-\mathrm{S}$ bonds between cysteine residues, ${ }^{132}$ a process that is reinforced during epididymal maturation. Once spermatozoa enter the oocyte at fertilization, its sperm head decondenses to form the male pronucleus, an essential event towards the formation of the zygote. ${ }^{133}$ Methods for assessing decondensation must therefore be considered useful for male fertility. Several groups have measured sperm chromatin decondensation by observing changes in size and shape of the sperm head by microscopic examinations when exposed to detergents (mostly sodium dodecylsulphate) and S-S bond reduction (using dithiothreitol), ${ }^{134,135,136}$ methods that can predict fertility in vitro. FC offers an excellent possibility to quantity events associated with chromatin decondensation. Zucker et al. ${ }^{137}$ detected head decondensation of rat and hamster spermatozoa prior to assessment by increases in light scattering. Samocha-Bone et al. ${ }^{138}$ evaluated decondensation with the help of acridine orange dye in human spermatozoa. Use of the dye PI with ethylenediaminetetraacetic acid and sodium dodecylsulphate is able to determine decondensation in boar spermatozoa. ${ }^{139}$ Thus, evaluation of decondensation of sperm heads by FC is an emerging but non-established technique for assessing male fertilizing potential.

\section{Detection of oxidative stress and lipid peroxidation}

Oxidative stress may be defined as an imbalance between production of reactive oxygen species (ROS) and the potentiality of antioxidants to scavenge these. A certain level of ROS is essential for sperm functions such as capacitation, acrosome reaction, sperm-oocyte fusion and protein tyrosine phosphorylation. ${ }^{140}$ However, it is a matter of concern that high levels of ROS have adverse effect on sperm functionality leading to high rate $(20 \%-40 \%)$ of infertility. ${ }^{141}$ From studies of different groups, it was found that ROS hamper the integrity of plasma membrane and nuclear DNA, leading to breakage of DNA and chromatin crosslinking. ${ }^{142}$ When the level of these breaks is high, it might lead to lowered fertility. ${ }^{143}$ Immature, morphologically

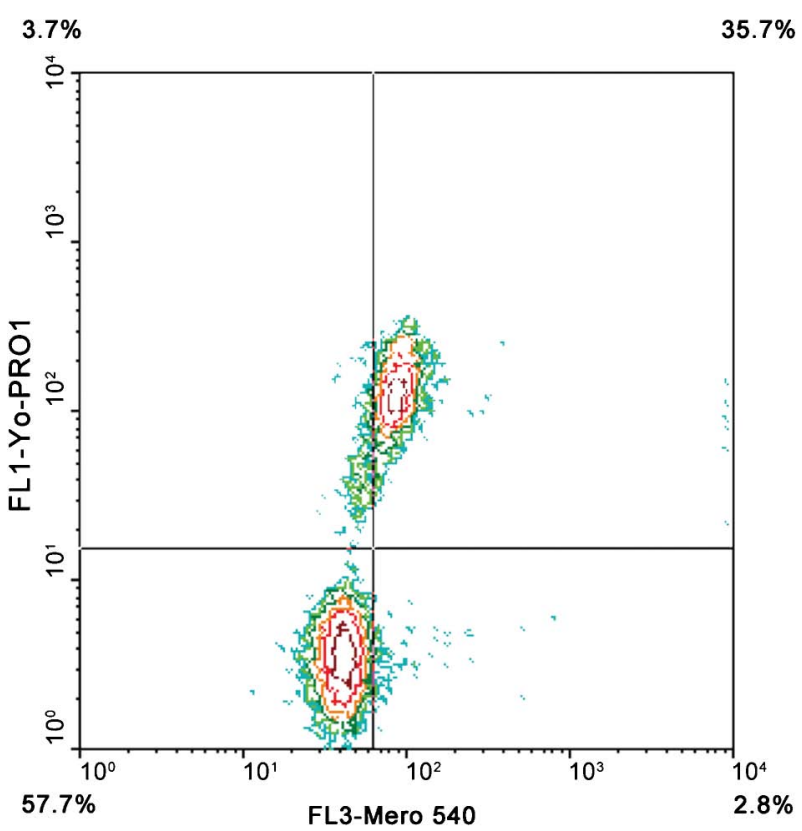

Figure 8 Plasma membrane asymmetry in a bull sperm sample measured by Merocyanine 540/YO-PRO-1 labeling. Contour plot shows viable cells with stable plasma membrane (lower left quadrant), viable cells with destabilized plasma membrane (lower right quadrant) and dead spermatozoa (upper left and right quadrants) abnormal spermatozoa and seminal leukocytes are the main sources of ROS in ejaculates. ${ }^{144}$ Numerous direct and indirect methods of ROS determination are available; however, direct in vivo determination is difficult as reactive oxidants are very unstable and generally have very short-lived intermediates. Determination of ROS directly in vivo might be done by the electron paramagnetic resonance spectroscopy, ${ }^{145}$ but due to the limitation of temperature and time, indirect methods are preferred. The chemiluminescence assay ${ }^{146}$ is one of the widespread used indirect methods of oxidative stress evaluation. And in this system, the two main dyes luminol and lucigenin in two different signaling processes are being used. Luminol follows an intracellular deoxygenation reaction, which is mediated by a heterogeneous group of sperm peroxidases, while lucigenin is oxidized at the extracellular level by the superoxide anion. ${ }^{147,148}$ Continuous discovery of new fluorochromes made it possible to analyze oxidative stress by FC. The $2^{\prime}, 7^{\prime}$-dichlorodihydrofluorescein diacetate is a nonspecific dye which could assess intracellular ROS in dog spermatozoa. ${ }^{149}$ This dye can be used together with viability dyes for removing the dead spermatozoa. ${ }^{150}$ Dihydroethidium (hydroethidine) may be used as a specific probe to detect superoxide anion (Figure 9); it is freely permeable and oxidized when bound to DNA, thus becoming valuable to detect superoxide anions in spermatozoa; ${ }^{151}$ however, other oxygen species might also be detected, depending on the filters used for detection. ${ }^{150}$ The MitoSOX (Invitrogen, Carlsbad, CA, USA) is another new probe able to detect mitochondrial superoxide in the live-cell population of human spermatozoa. ${ }^{152}$ The probe is readily oxidized by superoxide, while prevented by superoxide dismutase, thus enabling highly fluorescent oxidation products to be detectable upon binding to nucleic acid. However, most of these probes only measure the amount of lipid peroxidation but cannot locate where this peroxidation occurs. More precise and specific probes (4,5-diaminofluorescein diacetate, BODIPY and 5-iodoacetamidofluorescein;

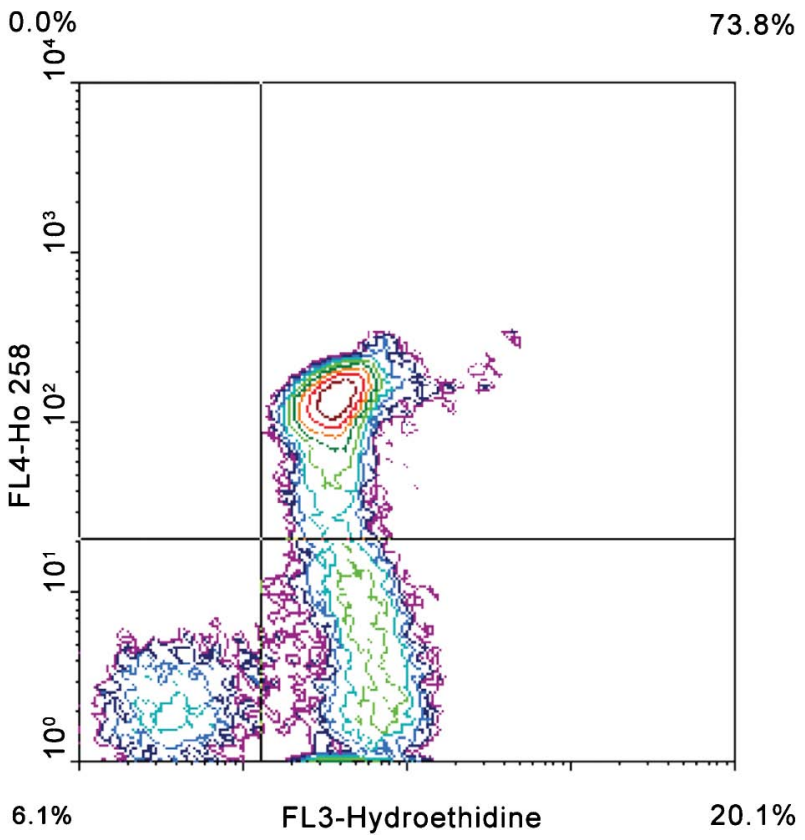

Figure 9 ROS analysis by hydroethidine and Hoechst 33258. Cells in the lower left quadrant are membrane-intact, negative for ROS production. Cells in the lower-right quadrant are membrane-intact, positive for ROS production. Cells in the upper-right quadrant have a damaged membrane and are positive for ROS production. ROS, reactive oxygen species. 
Invitrogen) to detect oxidative stress in spermatozoa are emerging. Among these, BODIPY became popular in andrology. ${ }^{153-157}$ BODIPY-based probes have high-quantum yield and high sensitivity of fluorescence, and the appearance of BODIPY-labeled spermatozoa can be regarded as an indication of physiologically relevant exposure of phospholipids to ROS. ${ }^{83}$ However, it is also assumed that FC-sperm sorting generates lipid pre-oxidation leading to oxidative stress, although there is no direct evidence on this prediction. Prior to FCsperm sorting, semen samples are highly extended beforehand disturbing the natural defense against oxidation. ${ }^{158}$ Levels of 8-hydrodeoxyguanosine have in human spermatozoa been shown to be highly correlated with DNA damage. ${ }^{159,160}$

\section{APPLICATION OF FC FOR THE SORTING OF SPERMATOZOA BY CHROMOSOMAL SEX}

The practical application of sexing spermatozoa, synergistically with other reproductive techniques, could improve the efficiency of animal production both in biological and economic terms. Selection of sex has important implications for populations in which one sex has more intrinsic value (e.g., rare animal genetic resources), for instance; stud operations and female dairy replacements, or the avoidance of males for pig production, etc. Sex preselection based on FC works on sperm DNA content measurement to facilitate sorting of $\mathrm{X}$ chromosome from the Y chromosome-bearing sperm. The X chromosome carries more DNA than that of the Y chromosome and the principle of FC sex sorting is based on this difference. In FC-based sex sorting, spermatozoa are firstly loaded with a fluorochrome. The non-intercalating vital fluorescent probe Hoechst 33342 is being used in FC-based sexing where it penetrates the sperm membrane and binds to the DNA. Droplets containing spermatozoa emitting an appropriate fluorescent signal in the FC acquire electrical charge and are sorted into collection tubes by an electromagnetic field. The development of high-speed sorting is one of the major developments of sorting technology, since the unique, asymmetric shape of mammalian spermatozoa makes conventional flow sorters less effective in sexing (Figure 10). Garner and Seidel ${ }^{161}$ have written a good historical overview. Offspring of predetermined sex using FC have been successfully produced using fresh and frozen-thawed spermatozoa in several mammalian species: pigs, ${ }^{162}$ cattle, ${ }^{163}$ sheep ${ }^{164}$ bottlenose dolphins, ${ }^{165}$ goat $^{166}$ and humans. ${ }^{167}$ Further refinements to standard FC technology included replacement of the beveled needle by an orientating nozzle with a ceramic tip giving sperm less time to lose orientation, which improved correct orientation of sperm to $70 \% .{ }^{168}$ Conversion to highspeed modified FC operating under increased pressure had improved the accuracy and efficiency (20 000-25000 events per second) of sperm sorting and purity of sorted population. ${ }^{169}$ Although it was recently reported by some groups that stressful process of sorting might weaken status of livestock spermatozoa, strategies for restoring and strengthening their potentials were also discussed. ${ }^{170}$ Besides evaluating sex chromosome content of individual spermatozoa, FC offers a precise tool to do quick cytogenetic analyses on sperm: aneuploidy can be detected based on DNA content of individual sperm cells. ${ }^{171,172}$

\section{THE 'DAMAGE UNDERESTIMATION' PROBLEM}

As it was indicated throughout the present review, one of the biggest challenges in applying FC in spermatology is the correct recognition of spermatozoa and the clear separation from signals of other particles present in the actual samples. With assays like the SYBR14/PI dye combination for viability measurements, it is relatively easy as every sperm cell is labeled with a DNA-specific fluorochrome, while other sperm-sized particles (like lipid droplets) are not. However, in some cases, certain sperm subpopulations remain unlabeled (like in simultaneous viability and acrosome integrity studies with FITC-PNA and PI) and cannot be separated from the signals of non-sperm particles due to their similar scatter properties, resulting in the overestimation of the unlabeled sperm subpopulation and a consequent underestimation of the others. In other cases, the applied fluorescent probes may have a nonspecific binding to the non-sperm particlesresulting in false-positive labeling. The FC seems to be overestimated by up to $10 \%$ the proportion of viable unstained spermatozoa while underestimating the damaged subpopulation. ${ }^{22}$ This, together with the variation that pipetting, might introduce when assessing sperm suspensions with low numbers needs further studies.

One approach to solve this 'damage underestimation' problem is to use positive labeling on every sperm cell. Thomas et al., ${ }^{64}$ for example, added SYTO 17, a DNA-specific, membrane permeable dye to the FITC-PNA/PI combination, to add a positive fluorescent signal to the otherwise unlabeled sperm subpopulation with intact plasma membrane and acrosome. Nagy et al. ${ }^{39}$ developed this approach further to use a similar dye combination which can be applied to FCs with a single, 488-nm laser line (the excitation and emission peaks of SYTO 17 are 621 and $634 \mathrm{~nm}$, respectively; therefore, it is not suitable for conventional bench-top instruments). In our laboratory, where we use a BD LSR FC equipped with three laser lines, we usually apply a DNAspecific, membrane permeable dye to label every sperm cell (as with the exception of pathological cases we do not expect to have other particles with DNA in the sperm samples) and add a fluorescent gate to the scatter gate to narrow our analysis to spermatozoa only, for example, Merocyanine 540/YO-PRO-1/Hoechst $33342^{50}$ where the Hoechst signal was used as fluorescent gate, or MitoTracker Deep Red 633 in combination with SYBR14, where the later was used to label every DNA-containing event. ${ }^{78}$ Obviously, this approach needs a larger, more expensive instrument, and cannot always be followed in laboratories equipped with smaller, single-laser FCs. As an alternative, the use of pretreatments and a mathematical model of alien particles can reduce particle misidentification, ${ }^{173}$ and can be performed in parallel with the functional assessment in the same FC. Another problem that may arise is that dyes label non-sperm elements, leading instead to overestimation of the population of dead cells. ${ }^{174}$

\section{FUTURE PERSPECTIVES FOR FC IN SPERMATOLOGY}

The main direction where the positive power of FC can be further expanded is the development of domain-specific multicolor assays for basic and applied spermatology. FC offers the opportunity to measure several sperm attributes on every single spermatozoon and on thousands of spermatozoa per sperm sample; therefore, it can improve semen quality control extremely. However, it is important to remember to measure attributes that are different and have low correlation with another. It is important to point out that due to differences in light sources, optical set-up and other adjustable parameters of the instruments, the analysis results at cellular level (the plots) are not easy to compare between laboratories. Thus, there is a need for validating each assay in the users own lab with the use of positive and negative controls. Multiparameter sperm studies by FC are not new: Graham et al. ${ }^{175}$ measured viability, acrosome integrity and mitochondrial membrane potential simultaneously. Newer fluorochromes with narrower emission spectra and novel FCs with several laser lines widen the possibilities further. We recently started to test a fluorescent probe to evaluate plasma membrane integrity by FC. The probe (Live/Dead 


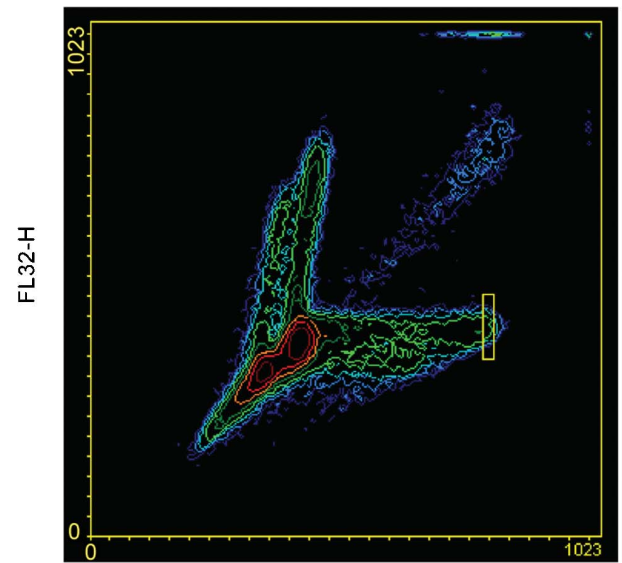

FL4-H

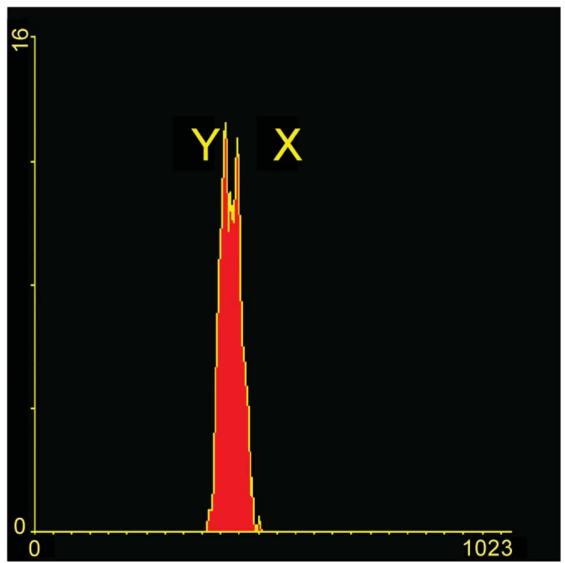

FL32-H

Figure 10 Separation of X-and Y-bearing spermatozoa with a conventional sorter flow cytometer, without orienting head. The majority of spermatozoa are not properly oriented, therefore excluded from analysis (sperm events outside of the yellow rectangular region on the left contour plot). Spermatozoa in the yellow region are gated to the histogram on the right.

Fixable Red Dead Cell Stain Kit, Invitrogen L-23102) has been applied in multiparameter fluorescent microscopy (Figure $11^{176}$ ) successfully. It has several advantages over the currently used FC viability assays: the probe labels both the viable and dead cells with the same color, but with different intensities (viable cells seem to be unlabeled when checked with fluorescent microscopy, but the dim fluorescence can be detected with FC). Therefore, only one detector is used for detecting viable and dead spermatozoa. Since the probe labels intracellular amides, it indicates the integrity of the plasma membrane over the whole cell surface, not just over the head domain as does the SYBR14/ PI combination. Finally, it is a fixable kit-fixing samples before FC analyses would offer a more flexible work schedule in the flow laboratory. Our first pilot experiments are promising (Figure 12).

Sperm function testing can be expected to shed light on the underlying reasons behind male infertility. ${ }^{177,178}$ It is expected that with the help of new probes a large number of new techniques will be adopted

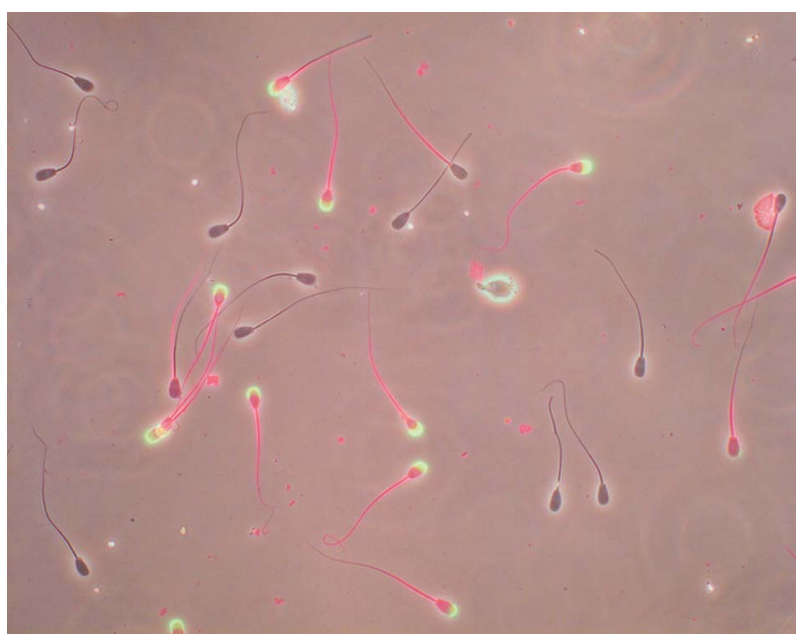

Figure 11 Merged fluorescent and DIC photos of bull spermatozoa labeled with Live/Dead Fixable Red Dead Cell Stain Kit (Invitrogen L-23102) and Alexa Fluor 488 PNA (L21409, green). Spermatozoa with intact plasma membrane and intact acrosome show no fluorescence, cells with disrupted plasma membrane show red tail and/or head and ruptured acrosomes are green. PNA, peanut agglutinin. to FC for spermatological analysis. For instance, FC determination of cytosolic calcium, protein tyrosine phosphorylation and cyclic adenosine monophosphate are being developed at our laboratory. To evaluate complex cellular system, multicolor FC can measure intracellular functional markers and cell signaling. Multiplexed bead assays which consists of a series of spectrally discrete particles, defined by either one-color fluorescence intensity or by a two-color fluorescence address, which can be used for capturing and quantitating soluble analytes, are suitable for measuring multiple DNA and RNA sequences or multiple proteins.

A new approach of statistical modem-based multiparametric clustering to identify cell subpopulation has been proposed. ${ }^{179}$ This robust clustering method is flexible and gives reproducible results. The novel ImageStream technology is combining FC with cell imaging parallel to quantification and visualization of spermatid-specific thioredoxin3 protein in defective spermatozoa. ${ }^{180}$ Cytometry imaging with

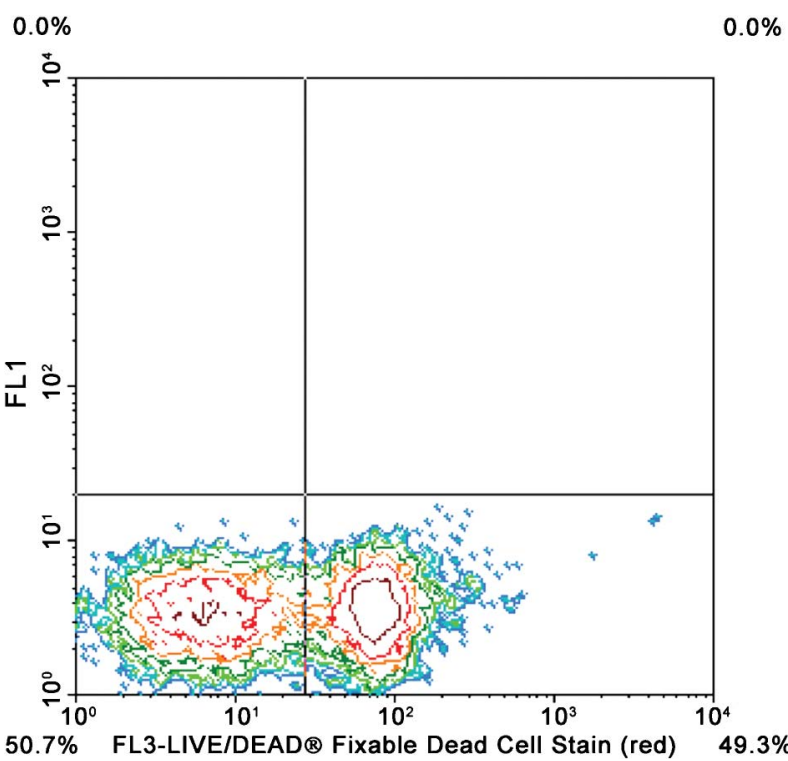

Figure 12 Contour plot shows spermatozoa labeled with Live/Dead Fixable Red Dead Cell Stain Kit (Invitrogen L-23102). Intact cells are in lower left quadrant and dead spermatozoa are in lower right quadrant. 
Table 1 Summary of sperm attributes and possible methods for evaluation

\begin{tabular}{ll}
\hline Sperm attribute & \multicolumn{1}{c}{ Possible methods } \\
\hline Enumeration of spermatozoa & True volumetric counting, fluorescent staining \\
Plasma membrane integrity & SYBR-14/PI, CFDA \\
Plasma membrane permeability and stability & Annexin V/PI, Hoechst 33342, YO-PRO-1, Merocyanine 540, SNARF-1, ethidium \\
& homodimer \\
Acrosome integrity & SYBR-14/PE-PNA/PI, FITC-PNA/PI, FITC-PSA/PI \\
Mitochondrial status & JC-1, Mitotracker Green, Mitotracker Deep Red \\
Chromatin intactness & SCSA, TUNEL, CMA3 \\
Apoptotic-like changes & Annexin V/PI, YO-PRO-1 \\
Oxidative stress & $\mathrm{H}_{2}$ DCFDA, HE, MITOSOX, BODIPY probes \\
\hline
\end{tabular}

Abbreviations: CFDA, carboxyfluorescein diacetate; CMA3, chromomycin A3; FITC, fluorescein isothiocyanate; $\mathrm{H}_{2}$ DCFDA, 2',7'-dichlorodihydrofluorescein diacetate; HE, hydroethidine; JC-1, 5, 5',6,6'-tetrachloro-1,1',3,3'-tetraethylbenzimidazolylcarbocyanine iodide; PE, phycoerythrin; PI, propidium iodide; PNA, peanut agglutinin; PSA, Pisum sativum agglutinin; SCSA, sperm chromatin structure assay; SNARF-1, seminaphtorhodafluor-1; TUNEL, terminal deoxynucleotidyl transferase-mediated dUTP nick end labeling.

charge-coupled device camera facilitate image of sperm, while they pass the laser beam. The possibilities of this new FC for sperm evaluation are infinite. ${ }^{181}$ The FC methods will probably further revolutionize our understanding of the sperm physiology and their functionality, and will undoubtedly extend its application in isolating many uncharacterized features of spermatozoa. Thus, future advancement of FC will continue to evolve as a major tool for spermatology at the single-cell level. In Table 1, we have summarized what we suggest as the best methods for particular properties/functions, as well as some alternative approaches.

\section{COMPETING FINANCIAL INTERESTS}

The authors declare no competing financial interests.

\section{ACKNOWLEDGMENTS}

This study was supported by the Swedish Farmer's Foundation for Agricultural Research and Vetenskapsrådet, Stockholm, Sweden. Scholarships from the Swedish Institute, Stockholm, Sweden, to Dr Md. Sharoare Hossain and Amanda Pimenta Siqueira, are acknowledged. Patuakhali Science and Technology University, Patuakhali, Bangladesh, is acknowledged for granting study leave to Dr Md. Sharoare Hossain.

1 Dziuk P. Factors that influence the proportion of offspring sired by a male following heterospermic insemination. Anim Reprod Sci 1996; 43: 65-88.

2 Rodriguez-Martinez H, Larsson B, Zhang BR, Söderquist L. In vitro assessment of viability and fertilizing capacity of bull spermatozoa. J Reprod Dev 1997; 43: 1-11.

3 Rodriguez-Martinez $\mathrm{H}$, Larsson $\mathrm{B}$. Assessment of sperm fertilizing ability in farm animals. Acta Agr Scand Sect A Anim Sci Supp/ 1998; 29: 12-8.

4 Saacke R, DeJarnette J, Bame J, Karabinus D, Whitman S. Can spermatozoa with abnormal heads gain access to the ovum in artificially inseminated super- and single-ovulating cattle? Theriogenology 1998; 50: 117-28.

5 Larsson $\mathrm{B}$, Rodríguez-Martínez $\mathrm{H}$. Can we use in vitro fertilization tests to predict semen fertility? Anim Reprod Sci 2000; 60-61: 327-36

6 Rodriguez-Martinez H. Evaluation of frozen semen: traditional and new approaches. In: Chenoweth PJ, editor. Topics in Bull Fertility, Recent Advance in Veterinary Medicine. Ithaca, NY: International Veterinary Information Services; 2000. Document No. A0502.0600. http://www.ivis.org

7 Rodríguez-Martínez H. Laboratory semen assessment and prediction of fertility: still utopia? Reprod Domest Anim 2003; 38: 312-8.

8 Popwell J, Flowers W. Variability in relationships between semen quality and estimates of in vivo and in vitro fertility in boars. Anim Reprod Sci2004; 81: 97-113.

9 Graham J, Mocé E. Fertility evaluation of frozen/thawed semen. Theriogenology 2005; 64: 492-504.

10 Gillan L, Evans G, Maxwell W. Flow cytometric evaluation of sperm parameters in relation to fertility potential. Theriogenology 2005; 63: 445-57.

11 Rodriguez-Martinez $\mathrm{H}$, Barth A. In vitro evaluation of sperm quality related to in vivo function and fertility. Soc Reprod Fertil Supp/ 2007; 64: 39-54.

12 Rodríguez-Martínez H. Can we increase the estimated value of semen assessment? Reprod Domest Anim 2006; 41 (Suppl 2): 2-10.
13 Rodríguez-Martínez H. State of the art in farm animal sperm evaluation. Reprod Fertil Dev 2007; 19: 91-101.

14 Rodríguez-Martínez H, Saravia F, Wallgren M, Roca J, Peña F. Influence of seminal plasma on the kinematics of boar spermatozoa during freezing. Theriogenology 2008; 70: 1242-50.

15 Amann RP. Weaknesses in reports of "fertility" for horses and other species. Theriogenology 2005; 63: 698-715.

16 Davis R, Gravance C. Standardization of specimen preparation, staining, and sampling methods improves automated sperm-head morphometry analysis. Fertil Steril 1993; 59: 412-7

17 Amann RP, Hammerstedt RH. In vitro evaluation of sperm quality: an opinion. J Androl 1993; 14: 397-406.

18 Pena F. Detecting subtle changes in sperm membranes in veterinary andrology. Asian $J$ Androl 2007; 9: 731-7.

19 Silva $\mathrm{P}$, Gadella B. Detection of damage in mammalian sperm cells. Theriogenology 2006; 65: 958-78.

20 Amann RP. Considerations in evaluating human spermatogenesis on the basis of total sperm per ejaculate. J Androl 2009; 6: 626-41.

21 Christensen P, Stryhn H, Hansen C. Discrepancies in the determination of sperm concentration using Bürker-Türk, Thoma and Makler counting chambers. Theriogenology 2005; 63: 992-1003.

22 Petrunkina A, Harrison R. Systematic misestimation of cell subpopulations by flow cytometry: a mathematical analysis. Theriogenology 2010; 73: 839-47.

$23 \mathrm{Lu} \mathrm{J}$, Chen F, Xu H, Wu Y, Xia X et al. Is flow cytometry really adapted to the determination of sperm concentration? Scand J Clin Lab Invest 2007; 67: 394-401.

24 Evenson D, Parks J, Kaproth M, Jost L. Rapid determination of sperm cell concentration in bovine semen by flow cytometry. J Dairy Sci 1993; 76: 86-94.

25 Christensen P, Stenvang J, Godfrey W. A flow cytometric method for rapid determination of sperm concentration and viability in mammalian and avian semen. $J$ Androl 2004; 25: 255-64.

26 Brando B, Göhde WJ, Scarpati B, D'Avanzo G. The "vanishing counting bead" phenomenon: effect on absolute $\mathrm{CD} 34^{+}$cell counting in phosphate-buffered salinediluted leukapheresis samples. Cytometry 2001; 43: 154-60.

27 Pintado B, de la Fuente J, Roldan ER. Permeability of boar and bull spermatozoa to the nucleic acid stains propidium iodide or Hoechst 33258, or to eosin: accuracy in the assessment of cell viability. J Reprod Fertil 2000; 118: 145-52.

28 Mátyus L, Szabó GJ, Resli I, Gáspár RJ, Damjanovich S. Flow cytometric analysis of viability of bull sperm cells. Acta Biochim Biophys Acad Sci Hung 1984; 19: 209-14.

29 Garner D, Pinkel D, Johnson L, Pace M. Assessment of spermatozoal function using dual fluorescent staining and flow cytometric analyses. Biol Reprod 1986; 34: 12738.

30 Riedy M, Muirhead K, Jensen C, Stewart C. Use of a photolabeling technique to identify nonviable cells in fixed homologous or heterologous cell populations. Cytometry 1991; 12: 133-9.

31 Garner D, Johnson L. Viability assessment of mammalian sperm using SYBR-14 and propidium iodide. Biol Reprod 1995; 53: 276-84.

32 Garner D, Dobrinsky J, Welch G, Johnson L. Porcine sperm viability, oocyte fertilization and embryo development after staining spermatozoa with SYBR-14. Theriogenology 1996; 45: 1103-13.

33 Songsasen N, Tong J, Leibo S. Birth of live mice derived by in vitro fertilization with spermatozoa retrieved up to twenty-four hours after death. J Exp Zool 1998; 280: 189-96.

34 Donoghue A, Garner D, Donoghue D, Johnson L. Viability assessment of turkey sperm using fluorescent staining and flow cytometry. Poult Sci 1995; 74: 1191-200.

35 Blanco J, Gee G, Wildt D, Donoghue A. Species variation in osmotic, cryoprotectant, and cooling rate tolerance in poultry, eagle, and peregrine falcon spermatozoa. Biol Reprod 2000; 63: 1164-71.

36 Collins A, Donoghue A. Viability assessment of honey bee, Apis mellifera, sperm using dual fluorescent staining. Theriogenology 1999; 51: 1513-23.

37 Collins A. Survival of honey bee (Hymenoptera: Apidae) spermatozoa stored at abovefreezing temperatures. J Econ Entomol 2000; 93: 568-71. 
38 Flajshans M, Cosson J, Rodina M, Linhart O. The application of image cytometry to viability assessment in dual fluorescence-stained fish spermatozoa. Cell Biol Int 2004; 28: 955-9.

39 Nagy S, Jansen J, Topper E, Gadella B. A triple-stain flow cytometric method to assess plasma- and acrosome-membrane integrity of cryopreserved bovine sperm immediately after thawing in presence of egg-yolk particles. Biol Reprod 2003; 68 1828-35.

40 Rodriguez-Martinez H, Tienthai P, Suzuki K, Funahashi H, Ekwall H et al. Involvement of oviduct in sperm capacitation and oocyte development in pigs. Reprod Supp/2001; 58: 129-45.

41 Reber F, Kasper M, Siegner A, Kniep E, Seigel G et al. Alteration of the intracellular pH and apoptosis induction in a retinal cell line by the AGE-inducing agent glyoxal. Graefes Arch Clin Exp Ophthalmol 2002; 240: 1022-32.

42 Peña F, Saravia F, Johannisson A, Walgren M, Rodríguez-Martínez H. A new and simple method to evaluate early membrane changes in frozen-thawed boar spermatozoa. Int J Androl 2005; 28: 107-14.

43 Holt W. Basic aspects of frozen storage of semen. Anim Reprod Sci 2000; 62: 3-22.

44 Agca Y, Liu J, Mullen S, Johnson-Ward J, Gould K et al. Chimpanzee (Pan troglodytes) spermatozoa osmotic tolerance and cryoprotectant permeability characteristics. J Androl 2005; 26: 470-7.

45 Ormerod M, Sun X, Snowden R, Davies R, Fearnhead H et al. Increased membrane permeability of apoptotic thymocytes: a flow cytometric study. Cytometry 1993; 14 595-602.

46 Wronski R, Golob N, Grygar E, Windisch M. Two-color, fluorescence-based microplate assay for apoptosis detection. Biotechniques 2002; 32: 666-8.

47 Bortner $\mathrm{C}$, Cidlowski J. Uncoupling cell shrinkage from apoptosis reveals that $\mathrm{Na}$ influx is required for volume loss during programmed cell death. J Biol Chem 2003 278: 39176-84.

48 Paasch U, Grunewald S, Wuendrich K, Jope T, Glander H. Immunomagnetic removal of cryo-damaged human spermatozoa. Asian J Androl 2005; 7: 61-9.

49 Peña F, Johannisson A, Wallgren M, Rodríguez-Martínez H. Assessment of fresh and frozen-thawed boar semen using an Annexin- $V$ assay: a new method of evaluating sperm membrane integrity. Theriogenology 2003; 60: 677-89.

50 Hallap T, Nagy S, Jaakma U, Johannisson A, Rodriguez-Martinez H. Usefulness of a triple fluorochrome combination Merocyanine 540/Yo-Pro 1/Hoechst 33342 in assessing membrane stability of viable frozen-thawed spermatozoa from Estonian Holstein Al bulls. Theriogenology 2006; 65: 1122-36.

51 Fraser L, Gorszczaruk K, Strzezek J. Relationship between motility and membrane integrity of boar spermatozoa in media varying in osmolality. Reprod Domest Anim 2001; 36: 325-9.

52 Yanagimachi R. Fertility of mammalian spermatozoa: its development and relativity. Zygote 1994; 2: 371-2.

53 Fraser L, Abeydeera L, Niwa K. Ca ${ }^{2+}$-regulating mechanisms that modulate bull sperm capacitation and acrosomal exocytosis as determined by chlortetracycline analysis. Mol Reprod Dev 1995; 40: 233-41.

54 Hossain MS, Afrose S, Sawada T, Hamano K, Tsujii H. Metabolism of exogenous fatty acids, fatty acid-mediated cholesterol efflux, PKA and PKC pathways in boar sperm acrosome reaction. Reprod Med Biol 2010; 9: 23-31.

55 Ohashi K, Saji F, Wakimoto A, Tsutsui T, Nakazawa T et al. Selection of acrosomereacted sperm with MH61-immunobeads. J Androl 1994; 15: 78-82.

56 Amin A, Bailey J, Storey B, Blasco L, Heyner S. A comparison of three methods for detecting the acrosome reaction in human spermatozoa. Hum Reprod 1996; 11 741-5

57 Samardzija M, Karadjole M, Getz I, Makek Z, Cergolj M et al. Effects of bovine spermatozoa preparation on embryonic development in vitro. Reprod Biol Endocrinol 2006; 4: 58.

58 Holden C, Trounson A. Staining of the inner acrosomal membrane of human spermatozoa with concanavalin A lectin as an indicator of potential egg penetration ability. Fertil Steril 1991; 56: 967-74.

59 Fukushima T, Kato M, Adachi T, Hamada Y, Horimoto M et al. Effects of sulfasalazine on sperm acrosome reaction and gene expression in the male reproductive organs of rats. Toxicol Sci 2005; 85: 675-82.

60 Pietrobon E, Domínguez L, Vincenti A, Burgos M, Fornés M. Detection of the mouse acrosome reaction by acid phosphatase. Comparison with chlortetracycline and electron microscopy. J Androl 2001; 22: 96-103.

61 Peña A, Johannisson A, Linde-Forsberg C. Post-thaw evaluation of dog spermatozoa using new triple fluorescent staining and flow cytometry. Theriogenology 1999; 52 965-80.

62 Cross N, Morales P, Overstreet J, Hanson F. Two simple methods for detecting acrosome-reacted human-sperm. Gamete Res 1986; 15: 213-26.

63 Graham J. Assessment of sperm quality: a flow cytometric approach. Anim Reprod Sci 2001; 68: 239-47.

64 Thomas C, Garner D, DeJarnette J, Marshall C. Fluorometric assessments of acrosomal integrity and viability in cryopreserved bovine spermatozoa. Biol Reprod 1997; 56 991-8.

65 Carver-Ward JA, Jaroudi KA, Hollanders JM, Einspenner M. High fertilization prediction by flow cytometric analysis of the CD 46 antigen on the inner acrosomal membrane of spermatozoa. Hum Reprod 1996; 11: 1923-8.

66 Petrunkina A, Gröpper B, Töpfer-Petersen E, Günzel-Apel A. Volume regulatory function and sperm membrane dynamics as parameters for evaluating cryoprotective efficiency of a freezing extender. Theriogenology 2005; 63: 1390406.
67 Flesch F, Voorhout W, Colenbrander B, van Golde L, Gadella B. Use of lectins to characterize plasma membrane preparations from boar spermatozoa: a nove technique for monitoring membrane purity and quantity. Biol Reprod 1998; 59 1530-9.

68 Szász F, Sirivaidyapong S, Cheng F, Voorhout W, Marks A et al. Detection of calcium ionophore induced membrane changes in dog sperm as a simple method to predict the cryopreservability of dog semen. Mol Reprod Dev 2000; 55: 289-98.

69 Ozaki-Kuroda K, Nakanishi H, Ohta H, Tanaka H, Kurihara $\mathrm{H}$ et al. Nectin couples cell-cell adhesion and the actin scaffold at heterotypic testicular junctions. Curr Bio 2002; 12: 1145-50.

70 Nagy S, Hallap T, Johannisson A, Rodriguez-Martinez H. Changes in plasma membrane and acrosome integrity of frozen-thawed bovine spermatozoa during a 4 h incubation as measured by multicolor flow cytometry. Anim Reprod Sci 2004; 80 225-35.

71 Gadella B, Harrison R. The capacitating agent bicarbonate induces protein kinase A dependent changes in phospholipid transbilayer behavior in the sperm plasma membrane. Development 2000; 127: 2407-20.

72 Aitken R, Ryan A, Baker M, McLaughlin E. Redox activity associated with the maturation and capacitation of mammalian spermatozoa. Free Radic Biol Med 2004; 36: 994-1010.

73 Ott M, Norberg E, Walter K, Schreiner P, Kemper $\mathrm{C}$ et al. The mitochondrial TOM complex is required for $\mathrm{tBid} / \mathrm{Bax}$-induced cytochrome $\mathrm{c}$ release. J Biol Chem 2007 282: 27633-9.

74 Peña F, Rodríguez Martínez H, Tapia J, Ortega Ferrusola C, González Fernández L et al Mitochondria in mammalian sperm physiology and pathology: a review. Reprod Domest Anim 2009; 44: 345-9.

75 Hu L, Wong P, Moore P, Bian J. Hydrogen sulfide attenuates lipopolysaccharideinduced inflammation by inhibition of p38 mitogen-activated protein kinase in microglia. J Neurochem 2007; 100: 1121-8.

76 Rasola A, Bernardi $P$. The mitochondrial permeability transition pore and its involvement in cell death and in disease pathogenesis. Apoptosis 2007; 12: 815-33.

77 Shivaji S, Kota V, Siva A. The role of mitochondrial proteins in sperm capacitation. J Reprod Immunol 2009; 83: 14-8.

78 Hallap T, Nagy S, Jaakma U, Johannisson A, Rodriguez-Martinez H. Mitochondria activity of frozen-thawed spermatozoa assessed by MitoTracker Deep Red 633 Theriogenology 2005; 63: 2311-22.

79 al-Rubeai M, Emery A, Chalder S, Goldman M. A flow cytometric study of hydrodynamic damage to mammalian cells. J Biotechnol 1993; 31: 161-77.

80 Evenson D, Darzynkiewicz Z, Melamed M. Simultaneous measurement by flow cytometry of sperm cell viability and mitochondrial membrane potential related to cell motility. J Histochem Cytochem 1982; 30: 279-80.

81 Troiano L, Granata A, Cossarizza A, Kalashnikova G, Bianchi R et al. Mitochondria membrane potential and DNA stainability in human sperm cells: a flow cytometry analysis with implications for male infertility. Exp Cell Res 1998; 241: 384-93.

82 Garner D, Thomas C, Joerg H, DeJarnette J, Marshall C. Fluorometric assessments of mitochondrial function and viability in cryopreserved bovine spermatozoa. Biol Reprod 1997; 57: 1401-6

83 Haugland RP. Probes for mitochondria. In: Spence MTZ, editor. The Handbook-A Guide to Fluorescent Probes and Labeling Technologies. 10th ed. Eugene, OR Molecular Probes Inc.; 2005. p1126.

84 Garner DL, Thomas CA. Organelle-specific probe JC-1 identifies memprane potentia differences in the mitochondrial function of bovine sperm. Mol Reprod Dev 1999; 53 222-9.

85 Martinez-Pastor F, Johannisson A, Gil J, Kaabi M, Anel L et al. Use of chromatin stability assay, mitochondrial stain JC-1, and fluorometric assessment of plasma membrane to evaluate frozen-thawed ram semen. Anim Reprod Sci 2004; 84 121-33

86 Kasai T, Ogawa K, Mizuno K, Nagai S, Uchida Y et al. Relationship between sperm mitochondrial membrane potential, sperm motility, and fertility potential. Asian Androl 2002; 4: 97-103

87 Gravance C, Garner D, Baumber J, Ball B. Assessment of equine sperm mitochondria function using JC-1. Theriogenology 2000; 53: 1691-703.

88 Kumaresan A, Kadirvel G, Bujarbaruah K, Bardoloi R, Das A et al. Preservation of boar semen at 18 degrees $C$ induces lipid peroxidation and apoptosis like changes in spermatozoa. Anim Reprod Sci 2009; 110: 162-71.

89 Salvioli S, Ardizzoni A, Franceschi C, Cossarizza A. JC-1, but not $\mathrm{DiOC}_{6}(3)$ or rhodamine 123 is a reliable fluorescent probe to assess DC changes in intact cells. FEBS Lett 1997; 411: 77-82.

90 Carrell D, Liu L, Peterson C, Jones K, Hatasaka H et al. Sperm DNA fragmentation is increased in couples with unexplained recurrent pregnancy loss. Arch Androl 2003, 49: 49-55.

91 Rodriguez-Martinez H, Courtens J, Kvist U, Plöen L. Immunocytochemical localization of nuclear protamine in boar spermatozoa during epididymal transit. J Reprod Fertil 1990; 89: 591-5.

92 Haines G, Hendry J, Daniel C, Morris I. Germ cell and dose-dependent DNA damage measured by the comet assay in murine spermatozoaa after testicular $\mathrm{X}$-irradiation. Biol Reprod 2002; 67: 854-61.

93 Cordelli E, Fresegna A, Leter G, Eleuteri P, Spanò M et al. Evaluation of DNA damage in different stages of mouse spermatogenesis after testicular $\mathrm{X}$ irradiation. Radiat Res 2003; 160: 443-51.

94 Aitken R, Krausz C. Oxidative stress, DNA damage and the $\mathrm{Y}$ chromosome. Reproduction 2001; 122: 497-506. 
95 Sakkas D, Moffatt O, Manicardi G, Mariethoz E, Tarozzi N et al. Nature of DNA damage in ejaculated human spermatozoa and the possible involvement of apoptosis. Biol Reprod 2002; 66: 1061-7

96 Young K, Robbins W, Xun L, Elashoff D, Rothmann S et al. Evaluation of chromosome breakage and DNA integrity in sperm: an investigation of remote semen collection conditions. J Androl 2003; 24: 853-61.

97 Purdy P. Ubiquitination and its influence in boar sperm physiology and cryopreservation. Theriogenology 2008; 70: 818-26.

98 Domínguez-Fandos D, Camejo M, Ballescà J, Oliva R. Human sperm DNA fragmentation: correlation of TUNEL results as assessed by flow cytometry and optical microscopy. Cytometry A 2007; 71: 1011-8.

99 Tavalaee M, Kiani A, Arbabian M, Deymeh MR, Hasan NE. Flow cytometry: a new approach for indirect assessment of sperm protamine deficiency. Int J Fertil Steril 2010; 3: 177-84

100 Evenson D, Darzynkiewicz Z, Melamed M. Relation of mammalian sperm chromatin heterogeneity to fertility. Science 1980; 210: 1131-3.

101 Evenson D, Wixon R. Clinical aspects of sperm DNA fragmentation detection and male infertility. Theriogenology 2006; 65: 979-91.

102 Spanò M, Cordelli E, Leter G, Lombardo F, Lenzi A et al. Nuclear chromatin variations in human spermatozoa undergoing swim-up and cryopreservation evaluated by the flow cytometric sperm chromatin structure assay. Mol Hum Reprod 1999; 5: 29-37.

103 Giwercman A, Lindstedt L, Larsson M, Bungum M, Spano M et al. Sperm chromatin structure assay as an independent predictor of fertility in vivo: a case-control study. Int J Androl 2010; 33: 221-7.

104 de Ambrogi M, Spinaci M, Galeati G, Tamanini C. Viability and DNA fragmentation in differently sorted boar spermatozoa. Theriogenology 2006; 66: 1994-2000.

105 Koonjaenak S, Johannisson A, Pongpeng P, Wirojwuthikul S, Kunavongkrit A et al. Seasonal variation in nuclear DNA integrity of frozen-thawed spermatozoa from Thai Al swamp buffaloes (Bubalus bubalis). J Vet Med A Physiol Pathol Clin Med 2007; 54: 377-83

106 Morrell J, Johannisson A, Dalin A, Hammar L, Sandebert T et al. Sperm morphology and chromatin integrity in Swedish warmblood stallions and their relationship to pregnancy rates. Acta Vet Scand 2008; 50: 2

107 Evenson D, Jost L, Corzett M, Balhorn R. Characteristics of human sperm chromatin structure following an episode of influenza and high fever: a case study. J Androl 2000; $21: 739-46$

108 Spjuth L, Johannisson A, Lundeheim N, Rodríguez-Martínez H. Early pre-pubertal exposure to low-dose oral di(2-ethylhexyl) phthalate does not affect sperm plasma membrane stability, acrosomal integrity or chromatin structure in the post-pubertal boar. Theriogenology 2007; 68: 186-95.

109 de Jonge C. Biological basis for human capacitation. Hum Reprod Update 2005; 11 : 205-14

110 O'Flaherty C, de Lamirande E, Gagnon C. Positive role of reactive oxygen species in mammalian sperm capacitation: triggering and modulation of phosphorylation events. Free Radic Biol Med 2006; 41: 528-40.

111 Tulsiani DR, Zeng HT, Abou-Haila A. Biology of sperm capacitation: evidence for multiple signaling pathways. Soc Reprod Fertil Supp/ 2007; 63: 257-72.

112 Harrison R, Gadella B. Bicarbonate-induced membrane processing in sperm capacitation. Theriogenology 2005; 63: 342-51.

113 Saravia F, Hernández M, Wallgren M, Johannisson A, Rodríguez-Martínez H. Controlled cooling during semen cryopreservation does not induce capacitation of spermatozoa from two portions of the boar ejaculate. Int J Androl 2007; 30: 485-99.

114 Muratori M, Porazzi I, Luconi M, Marchiani S, Forti G et al. AnnexinV binding and merocyanine staining fail to detect human sperm capacitation. J Androl 2004; 25: 797-810.

115 Pons-Rejraji H, Bailey J, Leclerc P. Cryopreservation affects bovine sperm intracellular parameters associated with capacitation and acrosome exocytosis. Reprod Fertil Dev 2009; 21: 525-37.

116 Piehler E, Petrunkina AM, Ekhlasi-Hundrieser M, Töpfer-Petersen E. Dynamic quantification of protein tyrosine phosphorylation of the sperm surface proteins during capacitation in vitro. Cytometry 2006; 69: 1062-70.

117 Sidhu K, Mate K, Gunasekera T, Veal D, Hetherington L et al. A flow cytometric assay for global estimation of tyrosine phosphorylation associated with capacitation of spermatozoa from two marsupial species, the tammar wallaby (Macropus eugenii) and the brushtail possum (Trichosurus vulpecula). Reproduction 2004; 127: 95103.

118 Gadella B, Miller N, Colenbrander B, van Golde L, Harrison R. Flow cytometric detection of transbilayer movement of fluorescent phospholipid analogues across the boar sperm plasma membrane: elimination of labeling artifacts. Mol Reprod Dev 1999; 53: 108-25.

119 Martí E, Pérez-Pé R, Muiño-Blanco T, Cebrián-Pérez J. Comparative study of four different sperm washing methods using apoptotic markers in ram spermatozoa. $J$ Androl 2006; 27: 746-53

120 Angelopoulou R, Plastira K, Msaouel P. Spermatozoal sensitive biomarkers to defective protaminosis and fragmented DNA. Reprod Biol Endocrinol 2007; 5: 36.

121 Moran J, Madejón L, Ortega Ferrusola C, Peña F. Nitric oxide induces caspase activity in boar spermatozoa. Theriogenology 2008; 70: 91-6.

122 Gadella B, Harrison R. Capacitation induces cyclic adenosine 3',5'-monophosphatedependent, but apoptosis-unrelated, exposure of aminophospholipids at the apical head plasma membrane of boar sperm cells. Biol Reprod 2002; 67: 340-50.

123 Watson P. The causes of reduced fertility with cryopreserved semen. Anim Reprod Sci 2000; 60-61: 481-92.
124 Ortega-Ferrusola C, García B, Gallardo-Bolaños J, González-Fernández L, RodríguezMartinez $\mathrm{H}$ et al. Apoptotic markers can be used to forecast the freezeability of stallion spermatozoa. Anim Reprod Sci 2009; 114: 393-403.

125 Januskauskas A, Johannisson A, Rodriguez-Martinez H. Subtle membrane changes in cryopreserved bull semen in relation with sperm viability, chromatin structure, and field fertility. Theriogenology 2003; 60: 743-58.

126 Bortner C, Cidlowski J. A necessary role for cell shrinkage in apoptosis. Biochem Pharmacol 1998; 56: 1549-59.

127 Jha R, Agarwal A, Mahfouz R, Paasch U, Grunewald S et al. Determination of poly (ADP-ribose) polymerase (PARP) homologues in human ejaculated sperm and its correlation with sperm maturation. Fertil Steril 2009; 91: 782-90.

128 Martínez-Pastor F, Aisen E, Fernández-Santos M, Esteso M, Maroto-Morales A et al. Reactive oxygen species generators affect quality parameters and apoptosis markers differently in red deer spermatozoa. Reproduction 2009; 137: 225-35.

129 Bratton S, MacFarlane M, Cain K, Cohen G. Protein complexes activate distinct caspase cascades in death receptor and stress-induced apoptosis. Exp Cell Res 2000; 256: 27-33.

130 Weil M, Jacobson M, Raff M. Are caspases involved in the death of cells with a transcriptionally inactive nucleus? Sperm and chicken erythrocytes. J Cell Sci 1998; 111 (Pt 18): 2707-15.

131 Lozano G, Bejarano I, Espino J, González D, Ortiz A et al. Relationship between caspase activity and apoptotic markers in human sperm in response to hydrogen peroxide and progesterone. J Reprod Dev 2009; 55: 615-21.

132 Bedford J, Calvin H. The occurrence and possible functional significance of -S-Scrosslinks in sperm heads, with particular reference to eutherian mammals. J Exp Zool 1974; 188: 137-55.

133 Sutovsky P, Schatten G. Depletion of glutathione during bovine oocyte maturation reversibly blocks the decondensation of the male pronucleus and pronuclear apposition during fertilization. Biol Reprod 1997; 56: 1503-12.

134 Rodriguez H, Ohanian C, Bustos-Obregon E. Nuclear chromatin decondensation of spermatozoa in vitro: a method for evaluating the fertilizing ability of ovine semen. Int J Androl 1985; 8: 147-58.

135 Chitale A, Rathaur R. Nuclear decondensation of sperm head and failure at in-vitro fertilization: an ultrastructural study. Hum Reprod 1995; 10: 594-8.

136 Reyes R, Sánchez-Vazquez M, Merchant-Larios H, Rosado A, Delgado N. Effect of heparin-reduced glutathione on hamster sperm DNA unpacking and nuclear swelling. Arch Androl 1996: 37: 33-45.

137 Zucker R, Perreault S, Elstein K. Utility of light scatter in the morphological analysis of sperm. Cytometry 1992; 13: 39-47.

138 Samocha-Bone D, Lewin L, Weissenberg R, Madgar Y, Soffer $Y$ et al. In-vitro human spermatozoa nuclear decondensation assessed by flow cytometry. Mol Hum Reprod 1998; 4: 133-7.

139 Córdova-Izquierdo A, Oliva J, Lleó B, García-Artiga C, Corcuera B et al. Effect of different thawing temperatures on the viability, in vitro fertilizing capacity and chromatin condensation of frozen boar semen packaged in $5 \mathrm{ml}$ straws. Anim Reprod Sci 2006; 92: 145-54.

140 Agarwal A, Allamaneni S. Role of free radicals in female reproductive diseases and assisted reproduction. Reprod Biomed Online 2004; 9: 338-47.

141 Gil-Guzman E, Ollero M, Lopez M, Sharma R, Alvarez J et al. Differential production of reactive oxygen species by subsets of human spermatozoa at different stages of maturation. Hum Reprod 2001; 16: 1922-30.

142 Said T, Aziz N, Sharma R, Lewis-Jones I, Thomas AJ et al. Novel association between sperm deformity index and oxidative stress-induced DNA damage in infertile male patients. Asian J Androl 2005; 7: 121-6.

143 Sharma R, Pasqualotto F, Nelson D, Thomas AJ, Agarwal A. The reactive oxygen species-total antioxidant capacity score is a new measure of oxidative stress to predict male infertility. Hum Reprod 1999; 14: 2801-7.

144 Aitken R, West K. Analysis of the relationship between reactive oxygen species production and leucocyte infiltration in fractions of human semen separated on Percoll gradients. Int J Androl 1990; 13: 433-51.

145 Swartz HM, Bolton JR, Borg DC. Biological Applications of Electron Spin Resonance. New York: Wiley-Interscience; 1972. p582.

146 Kobayashi H, Gil-Guzman E, Mahran A, Rakesh, Nelson D et al. Quality control of reactive oxygen species measurement by luminol-dependent chemiluminescence assay. J Androl 2001; 22: 568-74.

147 Aitken R, Buckingham D. Enhanced detection of reactive oxygen species produced by human spermatozoa with 7-dimethyl amino-naphthalin-1,2-dicarbonic acid hydrazide. Int J Androl 1992; 15: 211-9.

148 Aitken R, Buckingham D, West K. Reactive oxygen species and human spermatozoa: analysis of the cellular mechanisms involved in luminol- and lucigenin-dependent chemiluminescence. J Cell Physiol 1992; 151: 466-77.

149 Kim S, Yu D, Kim Y. Apoptosis-like change, ROS, and DNA status in cryopreserved canine sperm recovered by glass wool filtration and Percoll gradient centrifugation techniques. Anim Reprod Sci 2010; 119: 106-14.

150 Martinez-Pastor F, Mata-Campuzano M, Alvarez-Rodriguez M, Alvarez M, Anel L et al. Probes and techniques for sperm evaluation by flow cytometry. Reprod Domest Anim 2010; 45 (Suppl 2): 67-78.

151 Burnaugh L, Sabeur K, Ball B. Generation of superoxide anion by equine spermatozoa as detected by dihydroethidium. Theriogenology 2007; 67: 580-9.

152 Koppers A, de luliis G, Finnie J, McLaughlin E, Aitken R. Significance of mitochondrial reactive oxygen species in the generation of oxidative stress in spermatozoa. J Clin Endocrinol Metab 2008; 93: 3199-207. 
153 Brouwers J, Gadella B. In situ detection and localization of lipid peroxidation in individual bovine sperm cells. Free Radic Biol Med 2003; 35: 1382-91.

154 Ball B, Vo A. Detection of lipid peroxidation in equine spermatozoa based upon the lipophilic fluorescent dye C1I-BODIPY581/591. J Androl 2002; 23: 259-69.

155 Domínguez-Rebolledo ÁE, Martínez-Pastor F, Fernández-Santos MR, del Olmo E, Bisbal $\mathrm{S}$ et al. Comparison of the TBARS assay and BODIPY $\mathrm{C}_{11}$ probes for assessing lipid peroxidation in red deer spermatozoa. Reprod Domest Anim 2010; 45: e360-8

156 Guthrie H, Welch G. Use of fluorescence-activated flow cytometry to determine membrane lipid peroxidation during hypothermic liquid storage and freeze-thawing of viable boar sperm loaded with 4,4-difluoro-5-(4-phenyl-1,3-butadienyl)-4-bora3a,4a-diaza-s-indacene-3-undecanoic acid. J Anim Sci 2007; 85: 1402-11.

157 Aitken R, Wingate J, de luliis G, McLaughlin E. Analysis of lipid peroxidation in human spermatozoa using BODIPY C11. Mol Hum Reprod 2007; 13: 203-11.

158 Klinc $P$, Rath D. Reduction of oxidative stress in bovine spermatozoa during flow cytometric sorting. Reprod Domest Anim 2007; 42: 63-7.

159 de Iuliis GN, Thomson LK, Mitchell LA, Finnie JM, Koppers AJ et al. DNA damage in human spermatozoa is highly correlated with the efficiency of chromatin remodeling and the formation of 8-hydroxy-2'-deoxyguanosine, a marker of oxidative stress. Biol Reprod 2009; 3: 517-524.

160 Aitken RJ, de Iuliis GN. On the possible origins of DNA damage in human spermatozoa. Mol Hum Reprod 2010; 16: 3-13.

161 Garner D, Seidel GJ. History of commercializing sexed semen for cattle. Theriogenology 2008; 69: 886-95.

162 Grossfeld R, Klinc P, Sieg B, Rath D. Production of piglets with sexed semen employing a non-surgical insemination technique. Theriogenology 2005; 63 : 2269-77

163 Seidel GJ, Schenk J, Herickhoff L, Doyle S, Brink Z et al. Insemination of heifers with sexed sperm. Theriogenology 1999; 52: 1407-20.

164 de Graaf S, Evans G, Maxwell W, Cran D, O’Brien J. Birth of offspring of pre-determined sex after artificial insemination of frozen-thawed, sex-sorted and re-frozen-thawed ram spermatozoa. Theriogenology 2007; 67: 391-8.

165 O'Brien JK, Robeck TR. Development of sperm sexing and associated assisted assisted reproductiove technology for sex pre-selection of captive bottlenose dolphins (Tursiops truncatus). Reprod Fertil Dev 2006; 18: 319-29.
166 Parrilla I, Vazquez J, Roca J, Martinez E. Flow cytometry identification of X- and Ychromosome-bearing goat spermatozoa. Reprod Domest Anim 2004; 39: 58-60.

167 Fugger E. Clinical experience with flow cytometric separation of human X- and Y-chromosome bearing sperm. Theriogenology 1999; 52: 1435-40.

168 Johnson L, Welch $G$. Sex preselection: high-speed flow cytometric sorting of $X$ and $Y$ sperm for maximum efficiency. Theriogenology 1999; 52: 1323-41.

169 Maxwell W, Evans G, Hollinshead F, Bathgate R, de Graaf S et al. Integration of sperm sexing technology into the ART toolbox. Anim Reprod Sci 2004; 82-83: 79-95.

170 Vazquez J, Parrilla I, Roca J, Gil M, Cuello C et al. Sex-sorting sperm by flow cytometry in pigs: issues and perspectives. Theriogenology 2009; 71: 80-8.

171 Revay T, Nagy S, Kopp C, Flyckt A, Rens W et al. Macrocephaly in bull spermatozoa is associated with nuclear vacuoles, diploidy and alteration of chromatin condensation. Cytogenet Genome Res 2009; 126: 202-9.

172 Revay T, Kopp C, Flyckt A, Taponen J, Ijäs R et al. Diploid spermatozoa caused by failure of the second meiotic division in a bull. Theriogenology 2010; 73: 421-8.

173 Petrunkina A, Waberski D, Bollwein H, Sieme H. Identifying non-sperm particles during flow cytometric physiological assessment: a simple approach. Theriogenology 2010; 73: 995-1000.

174 Marchiani S, Tamburrino L, Giuliano L, Nosi D, Sarli V et al. Sumo1-ylation of human spermatozoa and its relationship with semen quality. Int J Androl; e-pub ahead of print 6 October 2010; doi: 10.1111/j.1365-2605.2010.01118.x.

175 Graham JK, Kunze E, Hammerstedt RH. Analysis of sperm cell viability, acrosomal integrity and mitochondrial function using flow cytometry. Biol Reprod 1990; 43: 55 64

176 Nagy S. Domain specific fluorescent labelling of bull spermatozoa. Magyar Allatorvosok Lapja 2007; 129: 464-7.

177 Lamb DJ. Semen analysis in 21st century medicine: the need for sperm function testing. Asian J Androl 2010; 12: 64-70.

178 Aitken RJ. Whither must spermatozoa wander? The future of laboratory seminology. Asian J Androl 2010; 12: 99-103.

179 Lo K, Brinkman R, Gottardo R. Automated gating of flow cytometry data via robust model-based clustering. Cytometry A 2008; 73: 321-32.

180 Buckman C, George T, Friend S, Sutovsky M, Miranda-Vizuete A et al. High throughput, parallel imaging and biomarker quantification of human spermatozoa by ImageStream flow cytometry. Syst Biol Reprod Med 2009; 55: 244-51.

181 Shapiro H. Practical Flow Cytometry. 3rd ed. New York: Wiley-Liss; 1995. p542. 